\title{
Propuesta de compartimentación estructural en la MASb 041.001 Sierra de Altomira: implicaciones hidrogeológicas
}

\author{
Jesús del Pozo Tejado(1), Miguel Mejías Moreno(1) y José Antonio Domínguez Sánchez ${ }^{(2)}$ \\ (1) Instituto Geológico y Minero de España, Ríos Rosas 23, 28003 Madrid \\ (2) Instituto Geológico y Minero de España, Unidad de Valencia \\ j.delpozo@igme.es; m.mejias@igme.es; ja.dominguez@igme.es
}

\begin{abstract}
RESUMEN
Desde la definición de los primeros sistemas acuíferos en Sierra de Altomira hasta la actual división en masas de agua subterránea MASb, los acuíferos diferenciados en esta sierra han sufrido constantes modificaciones en su extensión y modelo hidrogeológico conceptual. Incluso en la actualidad se plantean incertidumbres con respecto a su compartimentación interna a nivel hidrogeológico. A partir de un profundo análisis estructural sobre el origen y formación de las estructuras sedimentarias que hoy constituyen los niveles permeables de la MASb, se ha correlacionado el modelo tectónico resultante con la hidrogeología de la MASb Sierra de Altomira en general, y con su posible compartimentación interna en particular. El modelo estructural obtenido ha permitido distinguir diferentes zonas que, a escala local, presentan un comportamiento hidrogeológico diferente. La compartimentación propuesta se realiza a nivel regional, diferenciando dos grandes bloques estructurales: septentrional, meridional y, una escala mayor, con la definición de la Unidad Hidrogeológica Básica (UHB) como unidad mínima divisible en la que se identifican todos los componentes del modelo hidrogeológico conceptual. Esta división supone un importante punto de partida para la posterior interpretación del funcionamiento hidrogeológico local de la MASb Sierra de Altomira, si bien esta propuesta requiere de estudios complementarios para un mejor conocimiento de su hidrodinámica.
\end{abstract}

Palabras clave: Compartimentación de acuíferos, cuenca alta del Guadiana, hidrogeología, geología estructural, Sierra de Altomira.

\section{Structural compartmentation proposal in 041.001 Sierra de Altomira GWB: hydrogeological implications}

\begin{abstract}
From the definition of the first aquifer systems in the Sierra de Altomira to the current division in groundwater bodies (GWB), the aquifers defined in this zone have undergone constant changes in their extension and conceptual hydrogeological model. Even today there are uncertainties regarding its internal compartmentation at the hydrogeological level. From a deep structural analysis on the origin and formation of the sedimentary structures that today constitute the permeable levels of the GWB, the resulting tectonic model has been correlated with the hydrogeology of the Sierra de Altomira GWB in general, and with its possible internal compartmentalization in particular. The final structural model has allowed us to distinguish different zones, with repercussions in the local hydrogeology. This has identified sectors with different hydrogeological behaviour. The proposed compartmentation is done at different levels, from the two large northern and southern structural blocks, to the definition of the basic hydrogeological unit (BHU) as a minimum divisible unit in which all the components of the hydrogeological conceptual model are identified. This division is an important starting point for the subsequent definition of the hydrogeological functioning of the Sierra de Altomira GWB locally, although this proposal requires complementary studies for its full definition.
\end{abstract}

Keywords: aquifer compartimentation, upper Guadiana Basin, hydrogeology, structural geology, Sierra de Altomira. 
Jesús del Pozo Tejado, et al., 2019. Propuesta de compartimentación estructural en la... Boletín Geológico y Minero, 130 (2): $317-340$

\section{Introducción}

La Sierra de Altomira ha sido objeto de diversos estudios y controversias durante las últimas décadas, lo cual ha tenido reflejo en los numerosos modelos de evolución que intentan explicar la formación de este relieve. Se trata de una estructura compresiva peculiar, primero porque ocupa una posición intermedia entre el Sistema Central y la Cordillera Ibérica, con una dirección estructural "mezcla" de ambas y, en segundo lugar, porque los relieves que la componen presentan una dirección estructural intermedia entre los originados a partir de los esfuerzos béticos y pirenaicos. A la discusión de los diferentes modelos estructurales anteriores, hay que añadir las implicaciones geológicas e hidrogeológicas implícitas en esta estructura compleja.

En la MASb 041.001 Sierra de Altomira (objeto de este artículo) aún a día de hoy existen incertidumbres sobre sus límites hidrogeológicos, llegando incluso a plantearse la existencia de límites estructurales internos que compartimenten, de un modo funcional, la dinámica hidrogeológica del conjunto de la MASb. Este extremo es importante puesto que, a efectos de la gestión de las aguas subterráneas, esta será más eficaz en la medida que mejor sea conocido su funcionamiento hidrogeológico $y$, por ende, el volumen de recursos subterráneos disponible.

Resulta lógico pensar que el modelo de formación estructural de la Sierra de Altomira puede tener influencia en los aspectos geológicos e hidrogeológicos resultantes. A continuación se propone un modelo de compartimentación alternativo, justificado a partir de criterios geológicos-estructurales.

\section{Objetivos}

El objetivo principal de este trabajo es analizar la posible compartimentación interna de la MASb 041.001 Sierra de Altomira mediante criterios tectónico-estructurales, y proponer una alternativa a los modelos hidrogeológicos actuales que describen el funcionamiento de la misma.

A partir del modelo hidrogeológico conceptual propuesto, se plantea una nueva hipótesis de funcionamiento de este modelo, que aporta un punto de vista diferente a los ya expuestos en la extensa bibliografía existente al respecto (Sánchez-Soria, 1973; Muñoz-Martín, 1997; IGME 2009, 2011, 2013; MartínezParra, 2013; Martínez-Parra y Díaz-Muñoz, 2013); y que ha de servir, en última instancia, para optimizar la gestión hidrológica de la MASb Sierra de Altomira, y de la cuenca alta del Guadiana (CAG) en la que se integra.

\section{Metodología}

Como punto de partida, se ha analizado la amplia bibliografía reciente en la que se realiza un análisis exhaustivo de la hidrodinámica de la MASb a partir de datos piezométricos (IGME 2012, 2013, 2014, 2015b, 2016, y 2017a), de su hidrología superficial (IGME 2015c y 2017b) e incluso de la calidad de sus aguas (IGME 2015a).

Las redes de control piezométrica y foronómica operativas actualmente (IGME-CHG), han sido complementadas, ex profeso, con puntos de medida adicionales en aquellas zonas con ausencia de información. En la tabla 1 se incluye un resumen del número de puntos analizados para cada uno de los sectores posteriormente diferenciados.

Por otro lado, se ha hecho un análisis de la génesis y formación de la estructura litosférica de Sierra de Altomira s.s., tomando como base los modelos ya existentes (Guimerà y Álvaro, 1990; Muñoz-Martín, 1997; Muñoz-Martín y de Vicente, 1998), y se ha adaptado a los límites de la MASb de Sierra de Altomira. La información estructural profunda se ha completado, allí donde no había datos suficientes, a partir de numerosos trabajos (IGME e INYPSA, 2010; Biete et al., 2012; Piña-Varas, 2014; Valcárcel-Rodríguez, 2015).

Se obtiene, en definitiva, un modelo de compartimentación geológico-estructural de las MASb Sierra de Altomira que parte de modelos preestablecidos, y es complementado con aspectos específicos interpretados para este trabajo con fines hidrogeológicos.

En este artículo se exponen los aspectos tectónicos- estructurales que han servido de guía para el modelo de compartimentación propuesto. La relación de los datos hidrogeológicos concretos (piezometría,

\begin{tabular}{|c|c|c|}
\cline { 2 - 3 } \multicolumn{1}{c|}{} & \multicolumn{2}{|c|}{ PUNTOS DE CONTROL } \\
\cline { 2 - 3 } & Piezométrico & Foronómico \\
\cline { 2 - 3 } & 7 & 3 \\
\hline \multirow{3}{*}{ Sector I } & 5 & 3 \\
\hline Sector II & 27 & 8 \\
\hline Sector III & 25 & 5 \\
\hline Sector IV & 40 & 6 \\
\hline Sector V & 104 & 25 \\
\hline TOTAL & & \\
\hline
\end{tabular}

Tabla 1. Puntos de control analizados en cada uno de los sectores resultantes.

Table 1. Control points analyzed in each of the resulting sectors. 


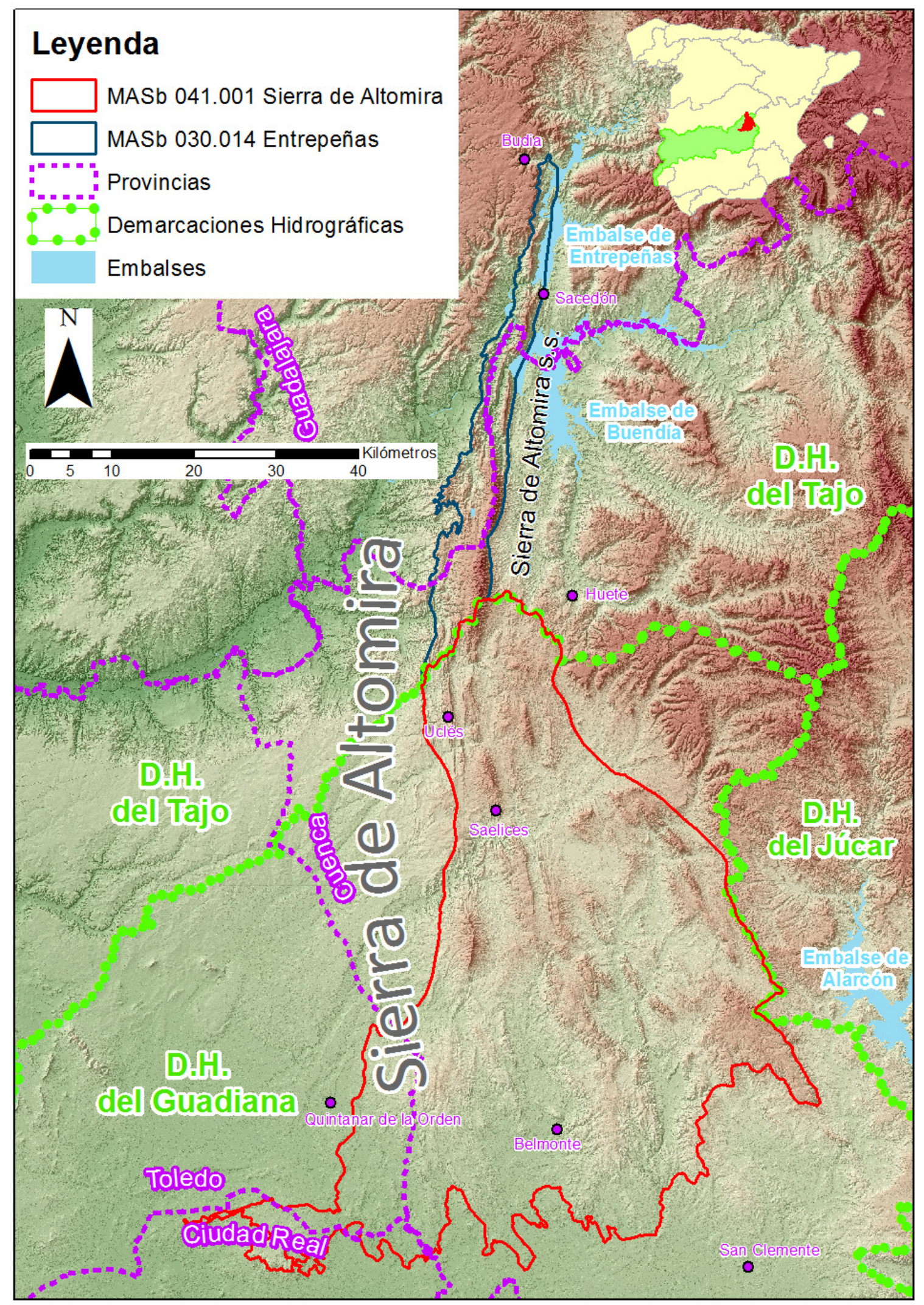

Figura 1. Localización geográfica de la MASb Sierra de Altomira (Demarcación Hidrográfica del Guadiana), con respecto al conjunto de la Sierra de Altomira.

Figure 1. Geographic location of the Sierra de Altomira GWB (Guadiana Basin) in the Sierra de Altomira complex. 
aforos, caracterización hidroquímica, implicaciones en los modelos de recarga y balances hidrológicos, etc.) con el modelo de compartimentación propuesto será objeto de la continuación de este trabajo.

\section{Localización y marco geográfico}

La Sierra de Altomira se sitúa en la submeseta sur de la península ibérica. Administrativamente, pertenece a la comunidad autónoma de Castilla-La Mancha y su extensión se reparte entre las provincias de Cuenca, Guadalajara, Ciudad Real y Toledo. La Sierra de Altomira s.s. se define en los relieves de mayor altitud situados al suroeste del embalse de Buendía, entre las poblaciones de Sacedón (en la provincia de Guadalajara) y Uclés (Cuenca) (Figura 1). Su prolongación hacia el sur continúa siendo Sierra de Altomira en términos geológicos-estructurales, aunque los relieves de esta se diversifican en diferentes ramas que han adquirido su propio nombre en la toponimia local, perdiéndose la identificación como Sierra de Altomira hacia el sur.

El ámbito espacial sobre el que trata este artículo se ciñe a la masa de agua subterránea 041.001 Sierra de Altomira (D.H. del Guadiana) que, a grandes rasgos, ocupa los dos tercios meridionales de los relieves que integran el conjunto de la Sierra de Altomira. Pertenece, mayoritariamente, a la provincia de Cuenca salvo su extremo suroccidental, que se adentra en las provincias de Toledo y Ciudad Real (Figura 1).

\section{Marcos geológico e hidrogeológico Marco geológico general}

La Sierra de Altomira s.s. se sitúa en una posición intermedia entre el Sistema Central y la Cordillera Ibérica, aunque estructuralmente se integra dentro de esta última (Figura 2). Concretamente, con respecto a

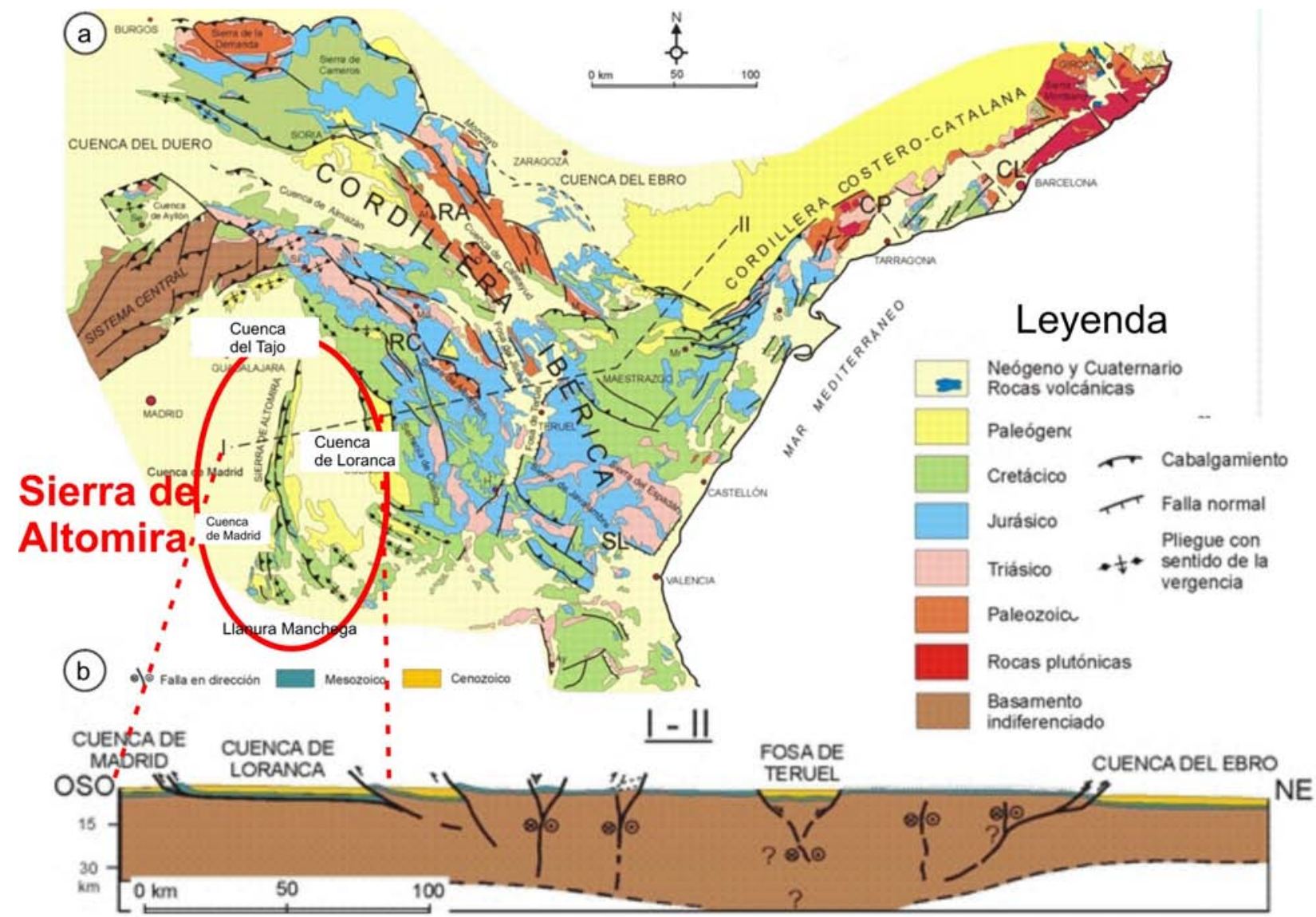

Figura 2. a) Situación de la Sierra de Altomira con respecto a la Cordillera Ibérica y Sistema Central. Véase la dirección estructural dominante de cada cadena; b) Corte geológico transversal de la Cordillera lbérica. (Modificado de Sopeña, 2004).

Figure 2. a) Position of Sierra de Altomira with respect to the Iberian Mountain Range and Central System. See the dominant structural direction of each chain; b) geological cross section of the lberian Mountain Range (modified from Sopeña, 2004). 
la Cordillera Ibérica, forma parte de su sector meridional o Rama Castellano-Valenciana y, dentro de esta, constituye el sector más occidental (Guimerà, 2004).

Está constituida por un conjunto de afloramientos lineales de materiales mesozoicos de dirección N-S a NNO-SSE, desde Budia (Guadalajara) hasta la línea imaginaria que une las poblaciones de Quintanar de la Orden-Belmonte-San Clemente (Álvaro y Capote, 1973). Sus límites quedan definidos, en el oeste, por la falla inversa de más de $1.500 \mathrm{~m}$ de salto, entre los materiales mesozoicos indeformados de la cuenca de Madrid y la cobertera deformada y aflorante de la Sierra de Altomira (Querol, 1989); en su margen oriental, el límite se establece en los últimos afloramientos mesozoicos previos al relleno terciario de la cuenca de Loranca (BOE-A-2013-5318, 2013); en el norte, el límite lo marca la depresión del Tajo y al sur, el límite queda fijado en el margen septentrional de la Llanura Manchega (Figura 2).

Desde el punto de vista geológico, está constituida por un cinturón de pliegues y cabalgamientos que implican a la cobertera mesozoico-terciaria, despegada del basamento Hercínico y del tegumento permotriásico a favor de la facies plástica del Keuper, configurando así un modelo estructural de piel fina "thin-skinned" (Sánchez-Soria, 1973; Muñoz-Martín, 1997; Guimerà, 2004) en la que la deformación implica exclusivamente a la cobertera sedimentaria, y no al basamento.

La estructura general de la serie mesozoica en

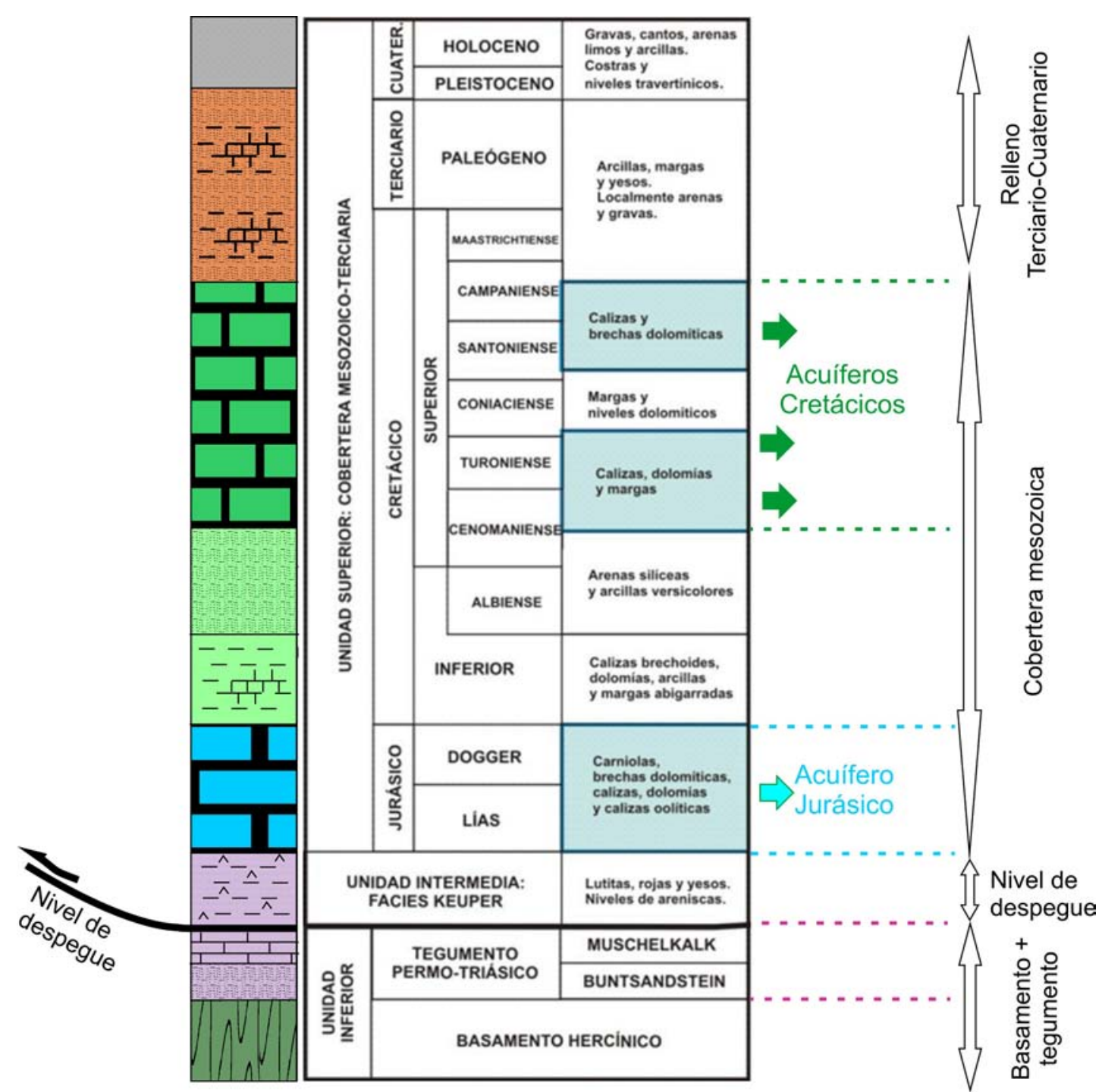

Figura 3. Unidades estratigráficas de la MASb Sierra de Altomira. Identificación de los niveles acuíferos jurásicos y cretácicos. Figure 3. Stratigraphic units in the Sierra de Altomira GWB. Jurassic and cretaceous aquifers. 
cada cinturón de pliegues la conforman uno o varios anticlinorios, constituidos por pliegues y cabalgamientos de marcada vergencia hacia el oeste, y de dirección general N-S. Muñoz-Martín (1997) diferencia tres sectores (septentrional, central y meridional) con características estructurales diferentes, separados entre sí por accidentes transversales y oblicuos (Sánchez-Soria, 1973; Muñoz-Martín, 1997; MuñozMartín y de Vicente, 1998).

La descripción de las unidades estratigráficas de la zona está suficientemente explicada en numerosas referencias bibliográficas (IGME 2009, 2014). En la figura 3 se resumen las características geológicashidrogeológicas de la columna estratigráfica "tipo" de la MASb Sierra de Altomira.

\section{Marco hidrológico}

Los principales ríos presentes en esta MASb son el Riansares, Gigüela, Záncara y Toconar-Saona, todos ellos afluentes del río Guadiana por su margen derecha.

Se puede apreciar una diferencia clara en la direc-

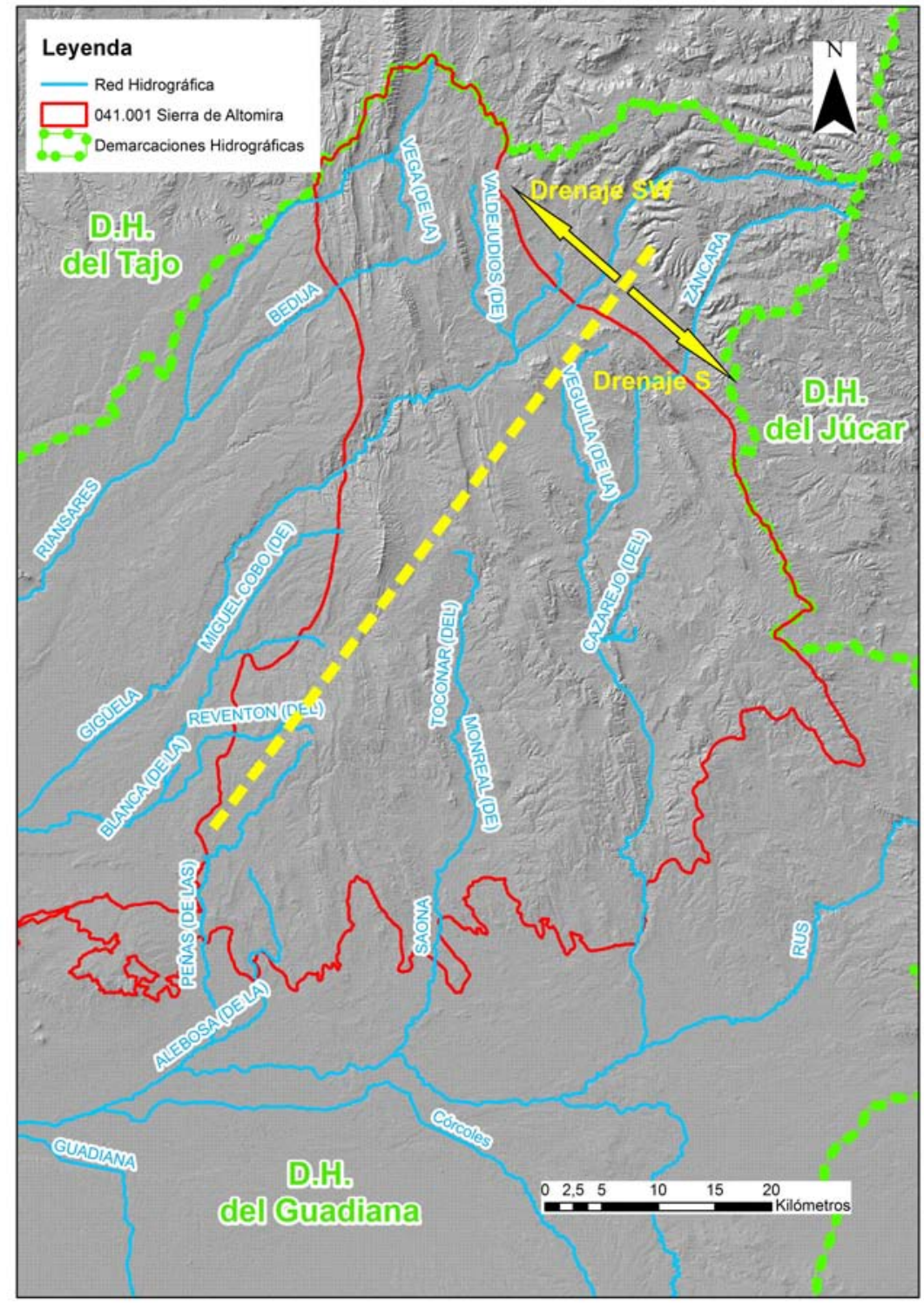

Figura 4. Principales ríos de la MASb Sierra de Altomira. Nótese la diferente dirección de drenaje superficial entre los ríos de las mitades septentrional y meridional.

Figure 4. Main rivers in the Sierra de Altomira GWB. Notice the different drainage direction between the north and the south half of the Sierra de Altomira GWB. 
ción de los cursos fluviales en función del sector de la MASb considerado (figura 4):

Los cursos fluviales de la mitad septentrional (Riansares y Gigüela) presentan una dirección NE-SO coincidente con la dirección de los accidentes oblicuos transversales de las fallas deTarancón y Gigüela, respectivamente; atraviesan las principales estructuras con la misma dirección, y dirigen su caudal hacia las MASb de Lillo-Quintanar y Consuegra-Villacañas, contiguas a la MASb Sierra de Altomira por el oeste.

Los ríos de la mitad meridional (Záncara y ToconarSaona) discurren en dirección N-S, de forma subparalela a las principales estructuras, hasta drenar su caudal en dirección sur hacia la Llanura Manchega (MASb Mancha Occidental II y Rus-Valdelobos).

\section{Marco hidrogeológico general}

La MASb 041.001 Sierra de Altomira se define a partir del conjunto de afloramientos mesozoicos situados entre las cuencas de Madrid al oeste, de Loranca al este, y la Llanura Manchega al sur. El límite norte queda establecido en la divisoria hidrográfica con la Demarcación del Tajo (Figura 2). Se sitúa, junto con las MASb de la Obispalía, Lillo-Quintanar y Consuegra-Villacañas, en el tercio septentrional de la cuenca alta del Guadiana (en adelante CAG). Limita al norte con la Demarcación Hidrográfica del Tajo, y al este con la del Júcar (Figura 5).

A nivel hidrogeológico, la CAG puede ser considerada como una unidad, atendiendo a las transferencias laterales de agua subterránea que se producen entre las MASb que la integran (Martínez-Cortina et al., 2011; Mejías, 2014). Así, el sector central de la CAG (surco manchego, compuesto por las MASb Mancha Occidental I, Mancha Occidental II y Rus-Valdelobos) se constituye como un auténtico "colector" de aguas subterráneas de las MASb periféricas, con un patrón de circulación subterránea en sentido este-oeste y aportes subterráneos desde las MASb situadas al norte (Sierra de Altomira principalmente), y Campo de Montiel al sur (Figura 5). En la MASb RusValdelobos se ha definido una divisoria de aguas sub-

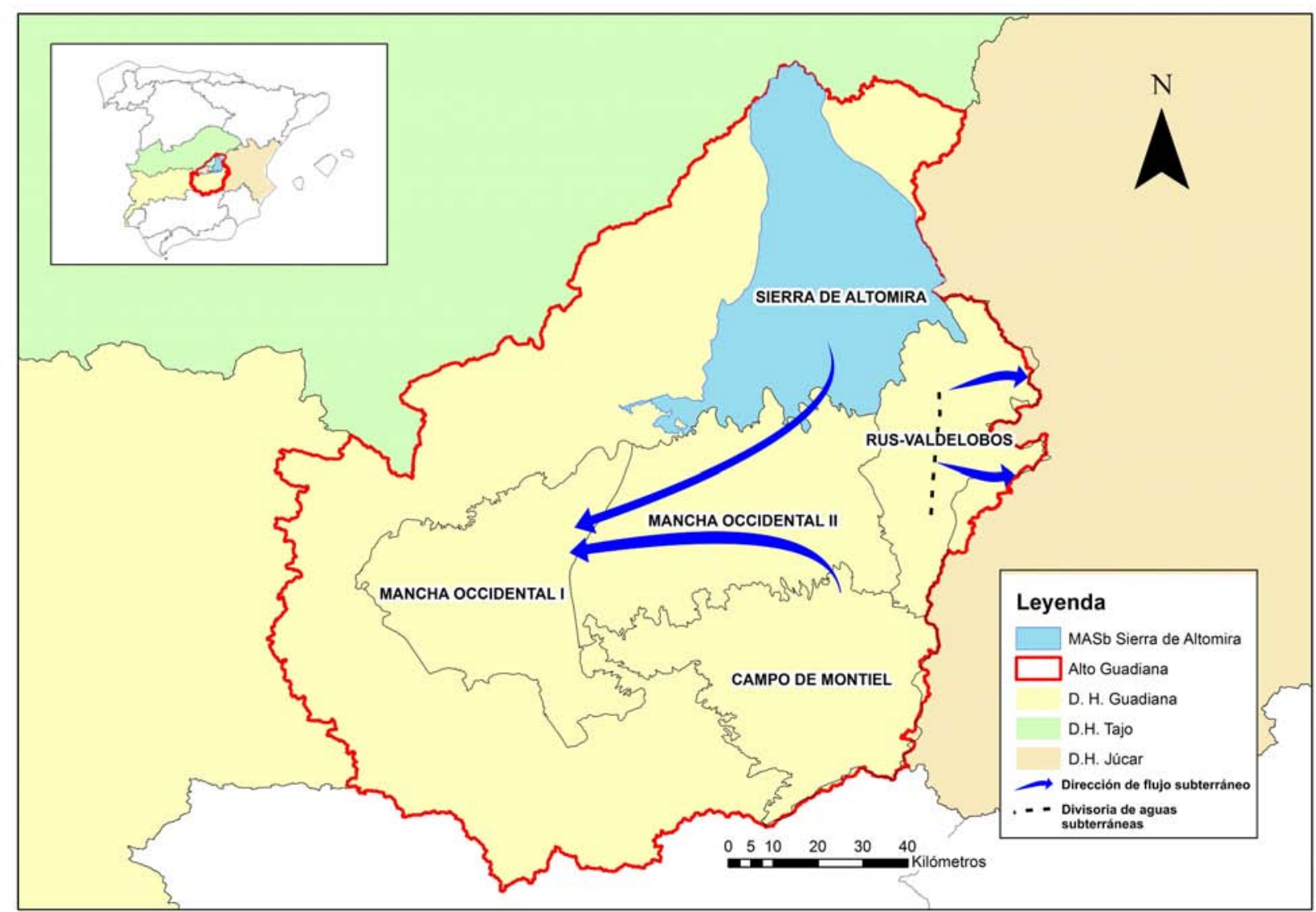

Figura 5. Localización de la MASb 041.001 Sierra de Altomira dentro de la CAG. Modelo de circulación de flujo subterráneo de la CAG. Figure 5. Location of the 041.001 Sierra de Altomira GWB in the Guadiana Upper Basin. Synthetic subterranean flux pattern in the Guadiana Upper Basin. 
Jesús del Pozo Tejado, et al., 2019. Propuesta de compartimentación estructural en la... Boletín Geológico y Minero, 130 (2): $317-340$

terráneas, al este de la cual el flujo subterráneo circula en sentido este, hacia la DH del Júcar (LópezGutiérrez et al., 2013).

\section{Estudio de la compartimentación hidrogeológica Antecedentes}

En los últimos años se han realizado varios estudios entre cuyos objetivos se encontraba la posible compartimentación hidrogeológica de la MASb Sierra de Altomira. De estos resultan diferentes modelos de compartimentación $y$, por ende, diferentes modelos hidrogeológicos conceptuales para el conjunto de la MASb. La nota común en todos ellos es la dificultad de establecer una compartimentación hidrogeológica fiable, dada la escasez de puntos de control, además de la incertidumbre, en muchos, de la identificación del horizonte acuífero controlado.

Las dificultades en la compartimentación tienen reflejo en las diferentes delimitaciones que han seguido los acuíferos de Sierra de Altomira. La primera definición del Sistema Acuífero $n^{\circ} 19$, Caliza de Altomira en el PNIAS (ITGE, 1979) engloba todos los niveles mesozoicos permeables de las actuales MASb Sierra de Altomira, la Obispalía y Rus-Valdelobos, además de la prolongación de la Sierra de Altomira por el norte hasta el embalse de Entrepeñas (Figura 6 a). Posteriormente, en el proceso de implantación de los planes hidrológicos según el RD 927/88 de 29 de julio del Reglamento de la Administración Pública del Agua y de la Planificación Hidrológica (BOE-A-198820883), se define la Unidad Hidrogeológica 04.01 Sierra de Altomira (Figura 6 b), delimitación que circunscribe, aproximadamente, a las actuales MASb Sierra de Altomira y Rus-Valdelobos, y ya se hace una distinción entre acuíferos jurásicos y cretácicos, separados por los materiales del Cretácico inferior, arenas de Utrillas y facies Weald (ITGE, 1997). Más recientemente, a raíz de la implantación de la Directiva Marco europea 2000/60/CE, en el PH del Guadiana 2009-2015 según el RD 354/2013 del 17 de mayo (BOE-A-20135318) se define la MASb 041.001 Sierra de Altomira, tal y como la conocemos hoy, diferenciada de la MASb 041.005 Rus-Valdelobos (Figura 6 c).

Tras la definición de la MASb, diversos trabajos han tratado sobre su compartimentación interna (IGME 2009, 2011, 2013; Martínez-Parra y Díaz-Muñoz, 2013), obteniéndose resultados diferentes en cuanto a la delimitación resultante, pero con una idea similar en cuanto al funcionamiento hidrogeológico conceptual.

En IGME (2009) e IGME (2011) se hace una propuesta de estructuración de la masa de agua en subsistemas acuíferos jurásicos, cretácicos y terciarios, a partir de la naturaleza de los materiales aflorantes, de su edad cronológica y del grado de explotación. Así, se obtienen diferentes bloques a los que se les asigna un funcionamiento hidrogeológico determinado, haciendo referencia únicamente en las zonas más superficiales de los diferentes acuíferos (Figura $6 \mathrm{~d}$ ).

En IGME (2013) se hace una nueva propuesta de compartimentación, en este caso basada en criterios hidrogeológicos (piezometría y calidad). De este trabajo resultan 4 zonas denominadas como subzona 01 a la subzona 04 , en las que se integran, aunque diferenciados, los niveles permeables jurásicos y cretácicos. En este caso se individualizan estos sectores a partir de desconexiones a favor de cabalgamientos, de forma lineal y continua de $\mathrm{N}$ a $\mathrm{S}$, haciéndose una evaluación de la fiabilidad del límite propuesto (Figura 6 e).

Los últimos trabajos relacionados con la hidrogeología de la Sierra de Altomira, e implícitamente de su compartimentación, se enmarcan dentro de las dos fases del Convenio específico de colaboración entre la Comunidad de Usuarios del Acuífero 19 Sierra de Altomira y el IGME, para el apoyo técnico en infraestructura hidrogeológica y aguas subterráneas 20122015 y 2016-2018. En estos trabajos, fundamentados en criterios piezométricos e hidrométricos, se hace un seguimiento de la evolución piezométrica en periodos de aguas altas y aguas bajas, diferenciado por acuíferos jurásicos y cretácicos (Figura 6 f). Se tiene así un seguimiento exhaustivo de la evolución hidrogeológica de los últimos años que supone una mejora considerable del conocimiento hidrogeológico que se tenía de la MASb hasta la fecha. En el último de estos informes (IGME, 2017a), ya se es capaz de fijar una serie de límites que compartimentan bloques jurásicos y cretácicos, que darían explicación a la evolución piezométrica de los últimos años (Figura 7 a y b). Asimismo, el control foronómico de los ríos de la MASb Sierra de Altomira permite establecer relaciones hidrogeológicas río-acuífero de gran interés (IGME, 2017b), como por ejemplo los tramos de los principales ríos con carácter predominantemente ganador o efluente o perdedor o influente, y su variabilidad temporal de este régimen dependiendo de las condiciones climatológicas (Figura $7 \mathrm{c}$ y d).

\section{Marco tectónico de la Sierra de Altomira}

El marco tectónico-estructural de la Sierra de Altomira se analiza en profundidad en la numerosa bibliografía existente (Sánchez-Soria, 1973; MuñozMartín, 1997; Muñoz-Martín y de Vicente, 1998; Capote et al., 2002; Valcárcel-Rodríguez, 2015). No 


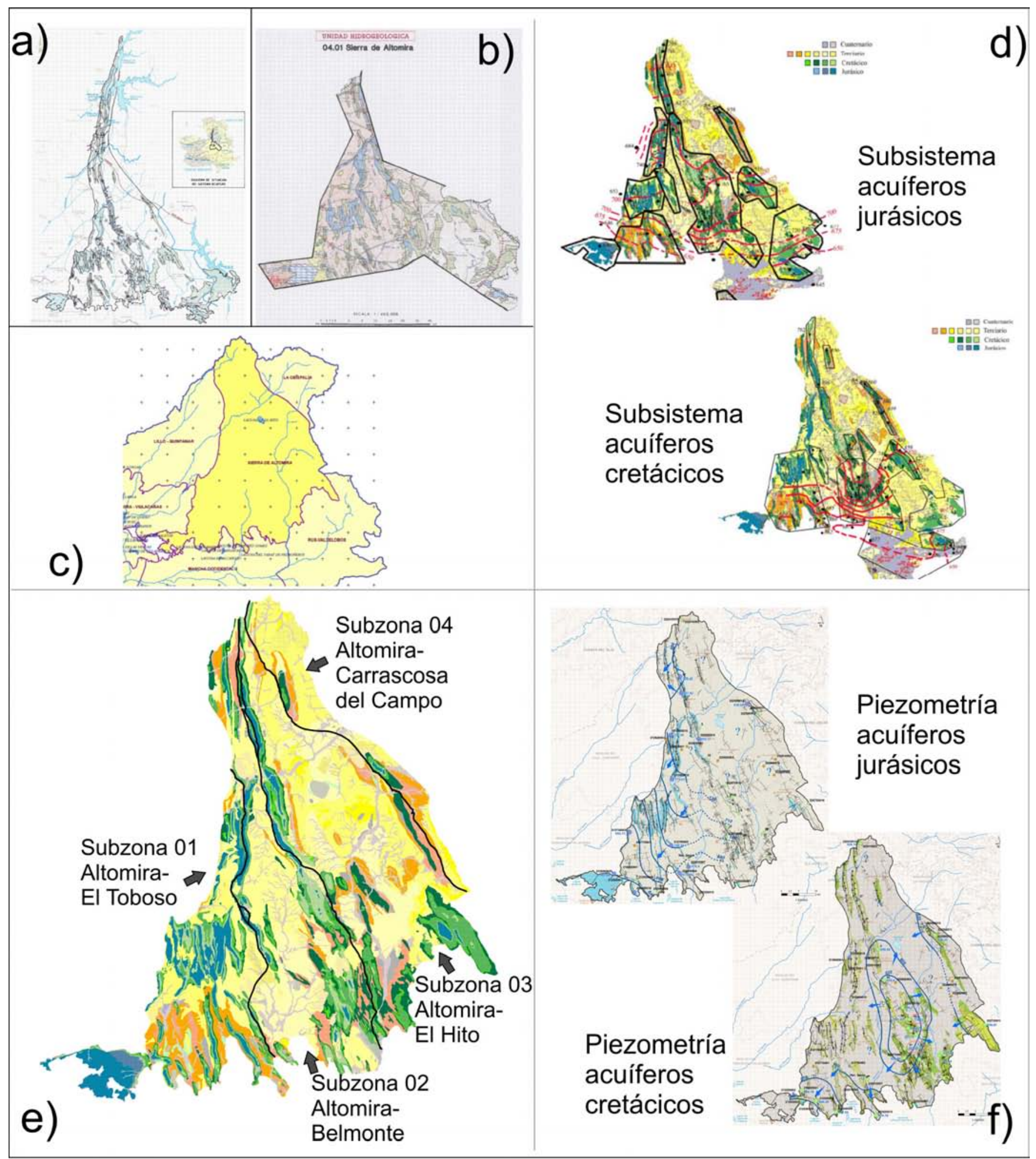

Figura 6. a) Sistema Acuífero $\mathrm{n}^{\circ} 19$ Caliza de Altomira (IGME, 1985); b) Unidad Hidrogeológica 04.01 Sierra de Altomira (ITGE, 1997); c) MASb 041.001 Sierra de Altomira (IGME y DGA, 2010); Subsistemas acuíferos jurásico y cretácico (IGME, 2011); e) Subzonas 01 a 04 (IGME, 2013); f) Piezometría de acuíferos jurásicos y cretácicos (IGME, 2015b).

Figure 6. a) Aquifer System $n^{\circ} 19$ Caliza de Altomira (IGME, 1985); b) Hidrogeological Unit 04.01 Sierra de Altomira (ITGE, 1997); c) GWB 041.001 Sierra de Altomira (IGME-DGA, 2010); Jurassic subsystem and Cretaceous aquifers (IGME, 2011); e) Zones 01 a 04 (IGME, 2013 ); f) Piezometric maps of the Jurassic and Cretaceous aquifers (IGME, 2015b). 


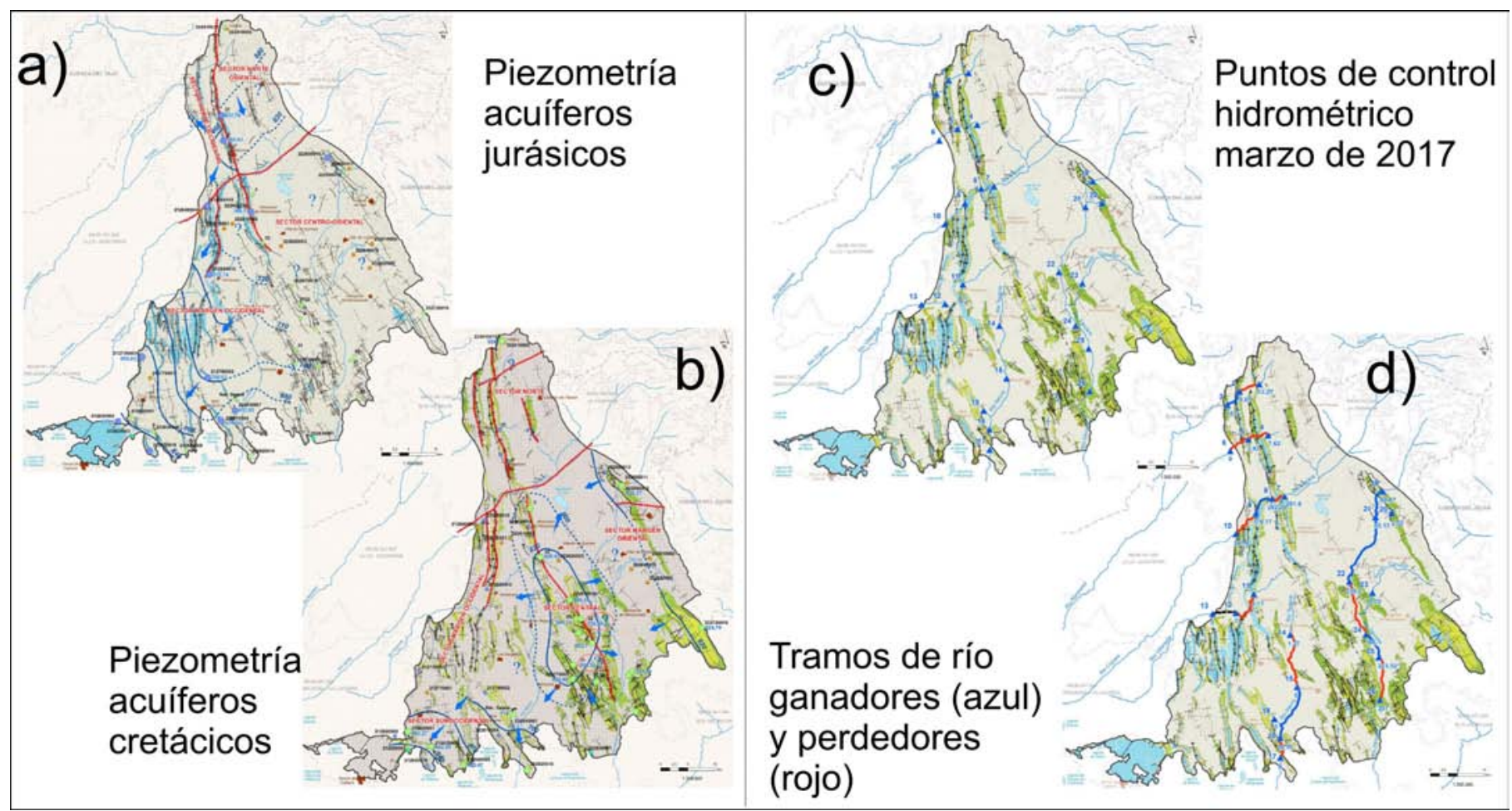

Figura 7. a) Piezometría del acuífero jurásico (marzo de 2017) y divisorias hidrogeológicas que independizan sectores del acuífero jurásico. b) Piezometría del acuífero cretácico (marzo de 2017) y divisorias hidrogeológicas que independizan sectores del acuífero cretácico. c) Puntos de control foronómico en los principales ríos de la MASb 041.001 Sierra de Altomira d) tramos ganadores y perdedores a fecha de marzo de 2017 (IGME, 2017 a y b).

Figure 7. a) Piezometric Map (March 2017) and hydrogeological limits of the Jurassic aquifer. b) Piezometric Map (March de 2017) and hydrogeological limits of the Cretaceous aquifer. c) Gauging control points in the principal rivers of the GWB 041.001 Sierra de Altomira d) Influent and effluent river tracts in March 2017 (IGME, 2017 and b).

obstante, se considera necesario hacer aquí una breve exposición de los aspectos más relevantes que tendrán influencia en la propuesta de compartimentación y en el modelo hidrogeológico resultante.

La Sierra de Altomira pertenece a la unidad estructural de cinturones alpinos de deformación intrapla$c a$, junto con los más importantes, la Cordillera Ibérica y el Sistema Central. Presenta una dirección estructural N-S a NNO-SSE "intermedia" entre ambas directrices principales (NO-SE para la Cordillera Ibérica, y NE-SO para el Sistema Central), aunque estructuralmente se adscribe a la primera de ellas (Figura 2).

El estilo de deformación de la Cordillera Ibérica y, a la postre de la Sierra de Altomira, está condicionado por su estratigrafía y litología dominantes. Se identifican así tres grandes unidades tectono-estratigráficas con comportamiento mecánico diferente: unidad inferior, compuesta por el zócalo Hercínico y el tegumento compuesto por las unidades delTriásico inferior (Buntsandstain y Muschekalk); unidad intermedia compuesta por arcillas con intercalaciones evaporíticas de la facies Keuper (Triásico superior), que actúa como nivel de despegue de los cabalgamientos alpinos; unidad superior o cobertera compuesta por los sedimentos mesozoicos y cenozoicos que rellenan las cuencas, y que posteriormente son plegados y cabalgados durante el ciclo alpino de deformación (Guimerà, 2013).

Las unidades inferior y superior presentan estructuras desacopladas (modelo tectónico thin skinned), desplazada la unidad superior sobre la inferior a favor de la unidad intermedia representada por la facies plástica del Keuper. Sin embargo, resulta evidente la influencia de las estructuras del basamento en la formación de las estructuras de deformación de la cobertera.

Las zonas de fractura del basamento (interpretadas como escalones en su superficie) juegan un papel importante en la estructura geológica resultante: por un lado, controlan el espesor sedimentario de la cobertera mesozoica y cenozoica (unidad superior); por otro, controlan la posición, espaciado y orientación de los pliegues de la cobertera. 
Durante el ciclo alpino de deformación, las fallas normales en el basamento actúan como centros de nucleación de los pliegues y cabalgamientos de la cobertera que definen la MASb Sierra de Altomira (figura 8) (Biete et al., 2012; Muñoz-Martín y de Vicente, 1998). La orientación de las fracturas del basamento con respecto a la dirección de esfuerzo compresivo afecta a las estructuras resultantes de la cobertera: así, direcciones de esfuerzo perpendiculares a dichas discontinuidades del basamento desarroIlan cabalgamientos de gran salto y pliegues verticalizados en la cobertera, mientras que direcciones oblicuas generan cabalgamientos de salto mínimo, pliegues tendidos y zonas de transferencia tectónica que cortan a las estructuras de deformación longitudinales (Sánchez-Soria, 1973; Muñoz-Martín, 1997; Muñoz-Martín y de Vicente, 1998).

La consecuencia inmediata de este modelo es la distribución heterogénea de las estructuras compresivas alpinas. Los esfuerzos compresivos alpinos se traducen en estructuras de deformación diferentes en función de la morfología del basamento (MuñozMartín y de Vicente, 1998), dando lugar a sectores con una estructura interna diferenciada. La deformación local resultante de la dinámica compresiva es consecuencia directa de los siguientes factores:

La magnitud del salto de la discontinuidad del basamento.

La orientación de esta discontinuidad con respecto a la dirección del esfuerzo compresivo dominante.

La presencia de zonas de transferencia tectónica que desplazan bloques entre sí y liberan energía de forma local.
En Muñoz-Martín (1997) y Muñoz-Martín y de Vicente (1998) se cuantifica la longitud de acortamiento tectónico consecuencia de la compresión alpina en la Sierra de Altomira a partir de la elaboración de cortes geológicos equilibrados (figura 8). En este trabajo se concluye que el mayor acortamiento tiene lugar en el extremo norte de la MASb Sierra de Altomira, que coincide con el sector central de Muñoz-Martín (1997), y este, se reduce progresivamente hacia el sur en la misma medida que varía la dirección estructural, de N-S en el norte a NO-SE hacia el sur. En el sector norte, por tanto, los cabalgamientos tienen un desplazamiento mayor, y los pliegues buzamientos más verticalizados. En la mitad sur, los cabalgamientos y pliegues reflejan un menor desplazamiento y una deformación más "suavizada".

Estudios específicos sobre zonas determinadas de Sierra de Altomira (IGME e INYPSA, 2010; Biete et al., 2012; Piña-Varas, 2014; Valcárcel-Rodríguez, 2015) han confirmado que las desconexiones tectónicas (con necesarias implicaciones hidrogeológicas) por efecto de los cabalgamientos y plegamientos alpinos, tienen su máximo desarrollo allí donde la dirección de esfuerzo tectónico incide de forma transversal (ortogonal) a la discontinuidad del basamento sobre la que se desarrollan (cortes B-B y C-C , Figura 9). En la medida en que la la dirección de esfuerzo es menos perpendicular a la discontinuidad del basamento, la estructura resultante se atenúa de forma que una desconexión tectónica evidente en la zona axial de un cabalgamiento puede perder continuidad en sus extremos (cortes A-A, D-D y E-E , Figura 9).

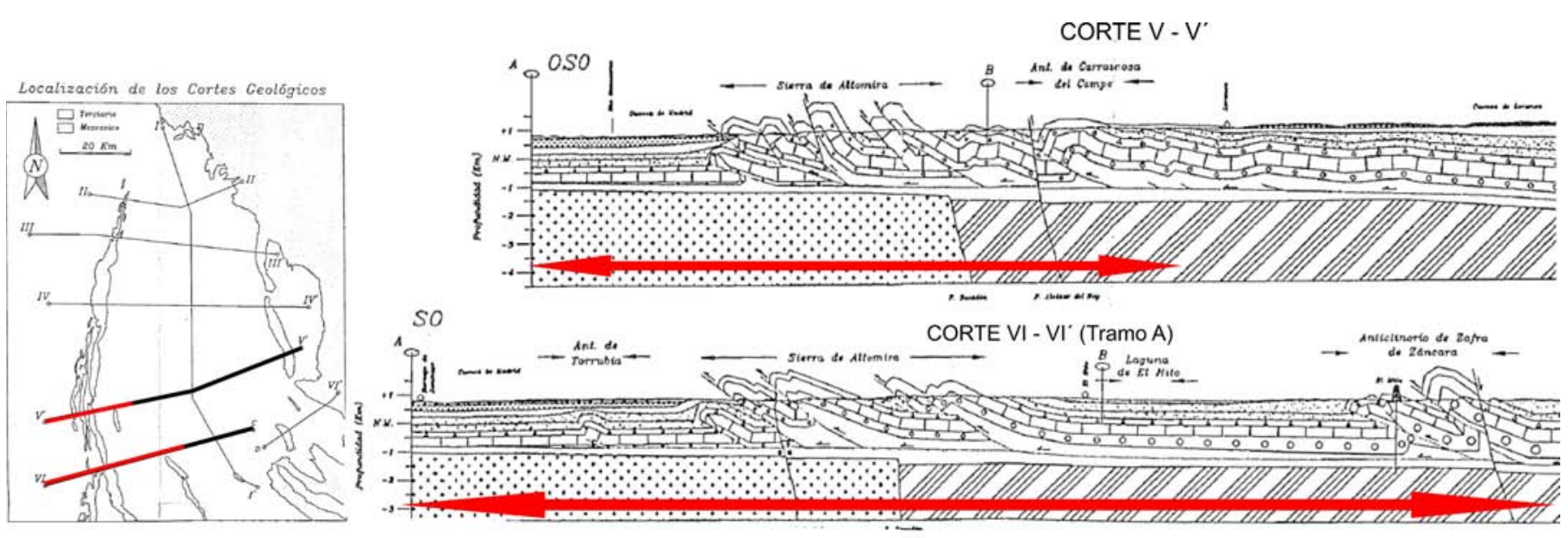

Figura 8. Cortes geológicos V-V y VI-VI, que representan el sector norte de la MASb 041.001 Sierra de Altomira (modificado de MuñozMartín, 1997).

Figure 8. Geological cross-sections V-V y VI-VI shown the northern part of the Sierra de Altomira GWB (modified from Muñoz-Martín, 1997). 


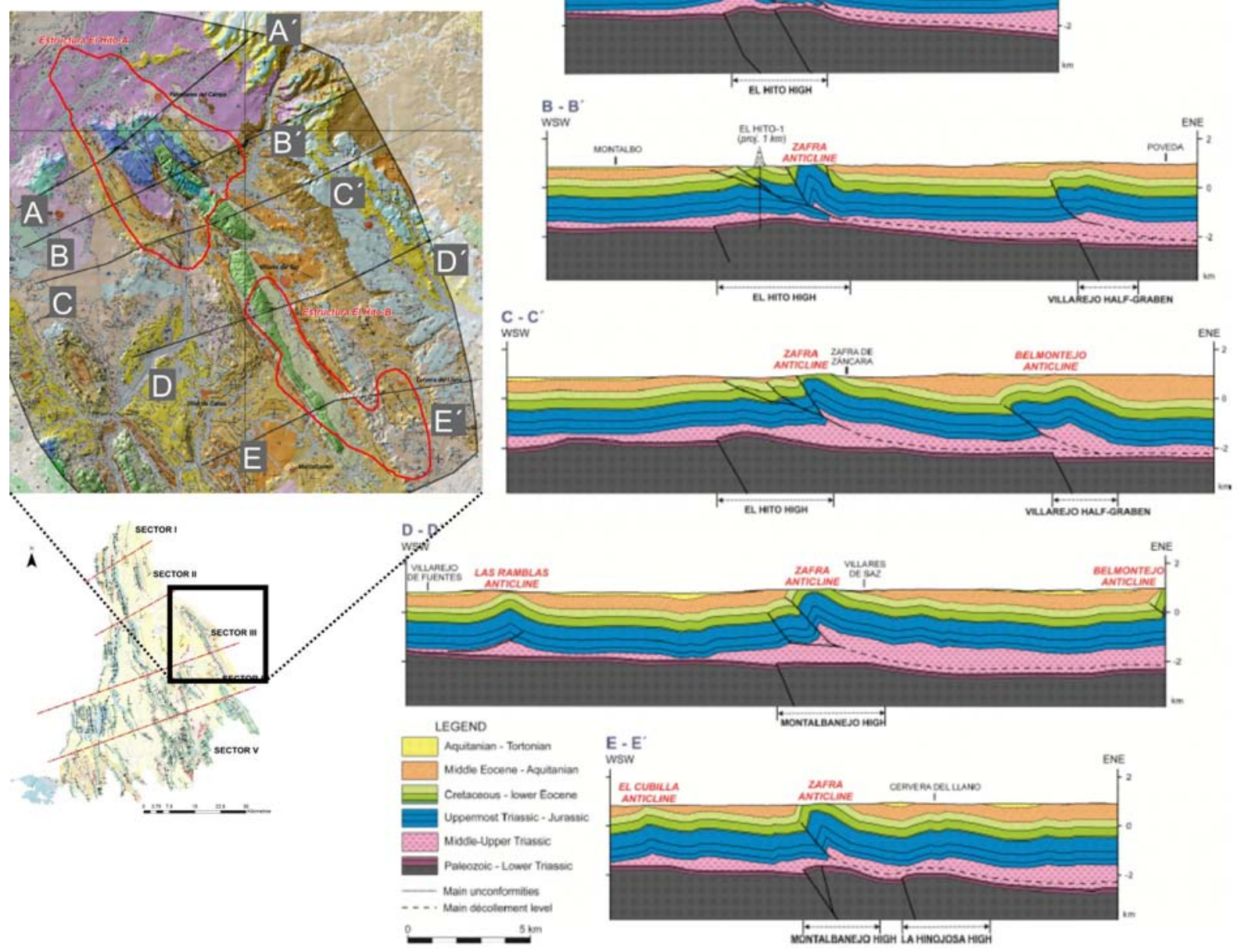

Figura 9. Cortes geológicos transversales a lo largo de la estructura del anticlinal de Zafra de Záncara (modificado de IGME e INYPSA, 2010).

Figure 9. Lengthwise geological cross-sections the Zafra de Záncara anticline (modified from IGME and INYPSA, 2010).

\section{Criterios aplicados en el análisis de la compartimen- tación}

\section{Criterio morfo-estructural en superficie}

Atendiendo al relieve en superficie, caracterizado por la posición, número, extensión y orientación de los anticlinorios mesozoicos, y de la disposición y morfología de las cuencas terciarias interpuestas, se pueden diferenciar 5 zonas (sectores I a V) en las que la morfología de la serie sedimentaria mesozoica difiere notablemente. En la figura 10 se identifican las diferentes unidades estructurales (afloramientos lineales mesozoicos y cuencas terciarias) que se pueden distinguir en cada sector.
Los 5 sectores anteriores tienen su origen en las particularidades tectónico-estructurales de la Sierra de Altomira ya descritas. La sucesión de varias fases de esfuerzos compresivos, NE-SO primero y E-O después, y la diferente evolución estructural según la intensidad y sentido de dichos esfuerzos sobre las rampas laterales del basamento, han dado lugar a una estructura compleja, en la que los niveles mesozoicos se encuentran fracturados y desplazados entre sí a partir de fallas transversales superficiales, y deformados en diferente grado (pliegues y cabalgamientos).

Esta deformación transversal se expone claramente en Muñoz-Martín (1997). En este trabajo el área estudiada abarcaba los relieves de la Sierra de 


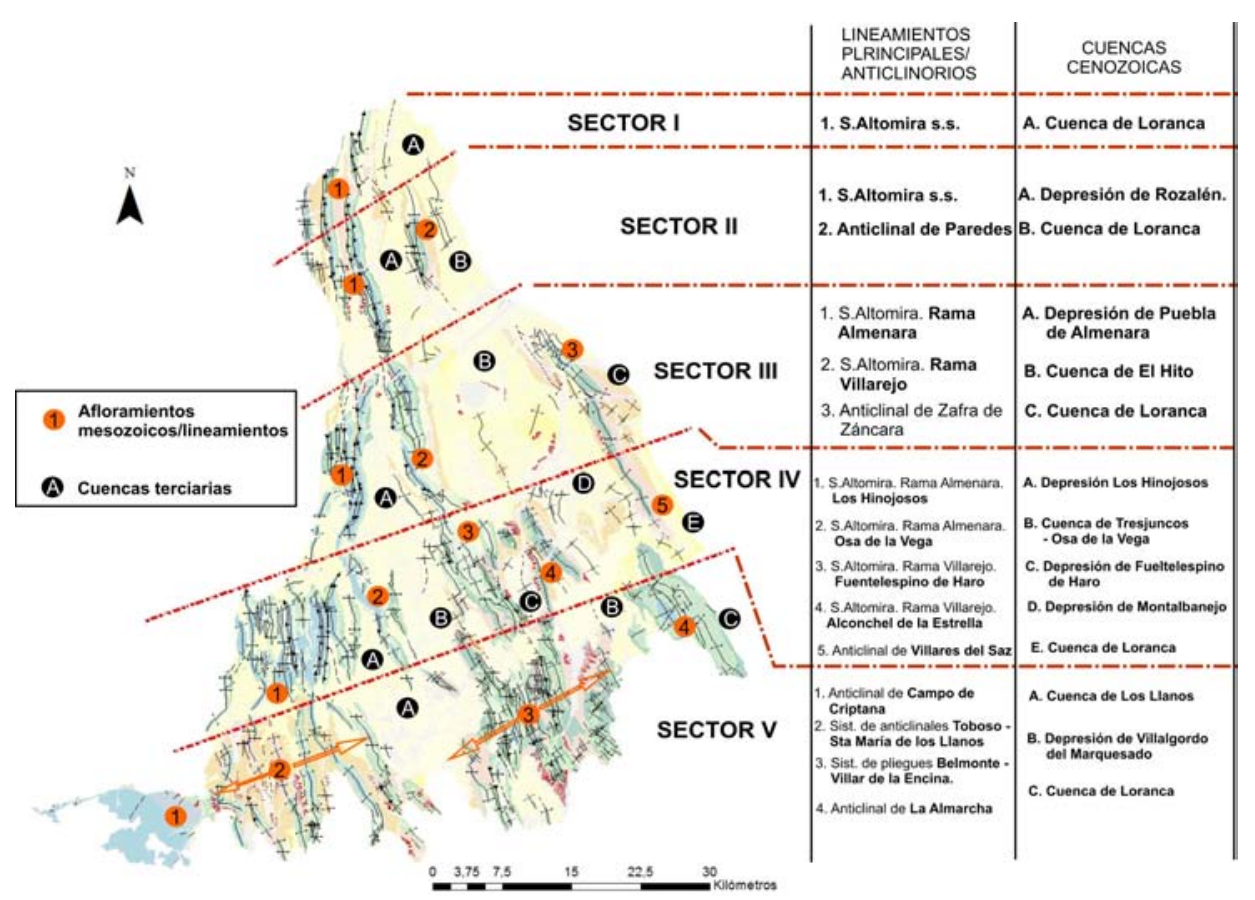

Figura 10. Identificación y localización de las principales unidades estructurales de la MASb Sierra de Altomira. Figure 10. Identification and location of the principal structural units of Sierra de Altomira GWB.

Altomira s.s. (Figura 1) desde su extremo más septentrional (en la cuenca del Tajo) hasta, aproximadamente, el sur de los afloramientos de los Hinojosos (Sector IV-1, Figura 10), ya en la cuenca del Guadiana (figura 11). Para este artículo se ha dado continuidad conceptual y espacial a la interpretación del trazado de fallas superficiales de Muñoz-Martín (1997) en el sector meridional, hasta abarcar el margen sur de la MASb Sierra de Altomira (Figura 11). Estas fallas superficiales actúan de transfer tectónicos y, a la postre, determinan las diferencias morfoestructurales entre los diferentes sectores I a V.

Entre las principales observaciones destacan:

La extensión transversal de los afloramientos mesozoicos en la MASb pasa de una anchura de 20 $\mathrm{km}$ en el sector I, hasta superar los $60 \mathrm{~km}$ en el sector $\mathrm{V}$, al sur.

El número de lineamientos mesozoicos en cada sector es progresivamente mayor, de norte a sur

La orientación de las estructuras se abre, en el mismo sentido, desde la dirección N-S en los extremos septentrional y occidental, hasta NNO-SSE en el sector oriental de la MASb (Figura 10).

Las divisorias entre bloques coinciden, a grandes rasgos, con zonas de transferencia tectónica (Sánchez-Soria, 1973; Muñoz-Martín, 1997), y separan sectores en los que la serie mesozoica presenta unas características estructurales y un grado de acortamiento diferentes.

\section{Criterio tectónico en profundidad}

Se ha hecho una interpretación de la estructura en profundidad, a partir del modelo tectónico aplicado para la formación y evolución de la estructura de la Sierra de Altomira.

En profundidad, la interpretación se fundamenta en la reconstrucción geológica de la estructura a partir de los cortes geológicos compensados de MuñozMartín (1997) de la figura 8, y de otros que se han publicado, utilizando como base los primeros, en zonas más específicas (IGME e INYPSA, 2010; Biete et al., 2012; Piña-Varas, 2014; Valcárcel-Rodríguez, 2015) (Figura 9).

Otro pilar fundamental para la reconstrucción de la estructura profunda han sido los mapas de isobatas del techo del basamento Varisco (Figura 13), contacto Triásico-Jurásico, discontinuidad JurásicoCretácico en el reflector de las arenas de Utrillas, y del contacto Cretácico-Terciario, procedentes del proyecto de almacenamiento de $\mathrm{CO}_{2}$ ALGECO2 (IGME e INYPSA, 2010), a partir de los cuales se han elaborado 4 perfiles geológicos-estructurales (Figura 12). En esta figura se observa que la arquitectura de las estructuras de deformación, en profundidad, es diferente en las mitades norte y sur de la MASb. Los perfiles 1 y 2 son representativos de la estructura interna de la mitad septentrional, mientras que los perfiles 3 y 4 lo son de la mitad meridional. Con respecto a los 


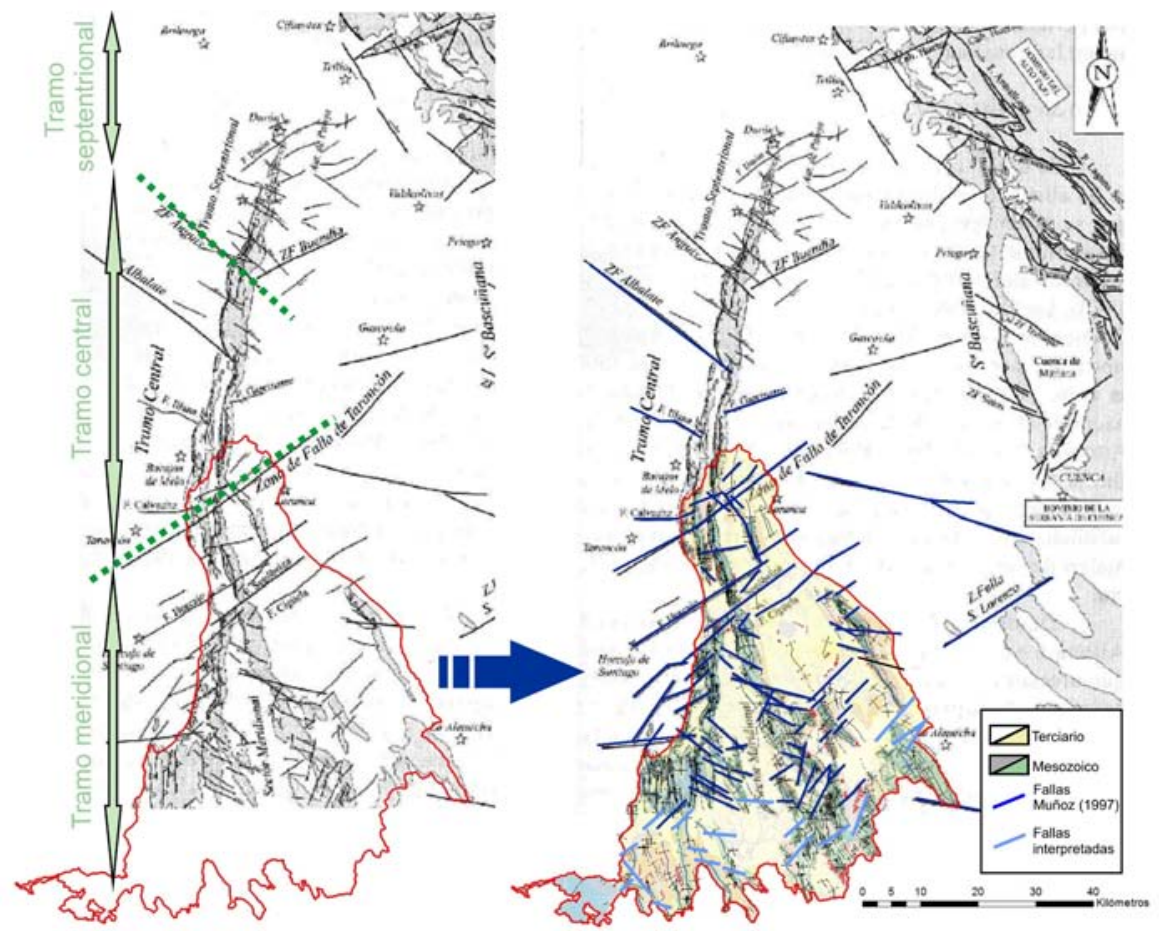

Figura 11. Sectorización y principales fallas superficiales (Muñoz-Martín, 1997). Aplicación a la MASb Sierra de Altomira. Figure 11. Sectorization and principal superficial foults (Muñoz-Martín, 1997). Application to the Sierra de Altomira GWB.

sectores I a V anteriores, el perfil 1 representa a los sectores I y II (similares estructuralmente), el perfil 2 al sector III, el perfil 3 al IV, y el perfil 4 al sector $V$.

A grandes rasgos, se observa que en la mitad septentrional la estructura es más verticalizada, y priman los cabalgamientos de gran desplazamiento. En este caso, los pliegues asociados son de flexión de falla y de propagación de falla. Mientras que en la mitad meridional los cabalgamientos son de menor recorrido, y toda la estructura mesozoica se encuentra más replegada, con buzamientos más suavizados y abundancia de pliegues menores que no llegan a aflorar.

\section{Modelo 3D del basamento}

La morfología del zócalo ha resultado tener una gran relevancia en la compartimentación hidrogeológica, puesto que condiciona (da origen y explicación) la arquitectura de las series mesozoica y cenozoica. Se ha realizado una modelización 3D de la superficie del basamento (Figura 12) a partir de los mapas de isobatas ya referidos (IGME e INYPSA, 2010). El techo del basamento se encuentra estructurado según una serie de horsts y grabens tectónicos que configuran su relieve como consecuencia de la reactivación de fracturas tardihercínicas durante la orogenia alpina. Las principales unidades diferenciadas en la morfología del zócalo se describen en la tabla 2:

Destaca que la orografía del techo del basamento es diferente en el norte y en el sur de la MASb Sierra de Altomira. La mitad septentrional representa una depresión relativa, con respecto a la mitad meridional en la que el techo del basamento se sitúa a una cota absoluta más elevada.

Al este de la MASb de Sierra de Altomira, fuera de sus límites, se sitúa la gran depresión del basamento que da lugar al potente relleno sedimentario mesozoico y cenozoico de la Cuenca de Loranca.

La nota común entre los sectores septentrional y meridional se encuentra en su margen occidental configurado por un alto estructural, si bien en la mitad meridional el basamento alcanza cotas absolutas más elevadas. Inmediatamente al este de este alto, en la mitad septentrional se describe una gran depresión (Depresión de El Hito), independizada de la gran depresión de la cuenca Loranca por el alto de Zafra de Záncara (Figura 12). En la mitad meridional, al este de los altos de los Hinojosos y de Campo de Criptana, se encuentra el altiplano de Haro y el alto de Alconchel, que mantienen el basamento a una cota relativamente elevada hasta el límite con el bloque hundido de la Cuenca de Loranca, al este de la MASb. 


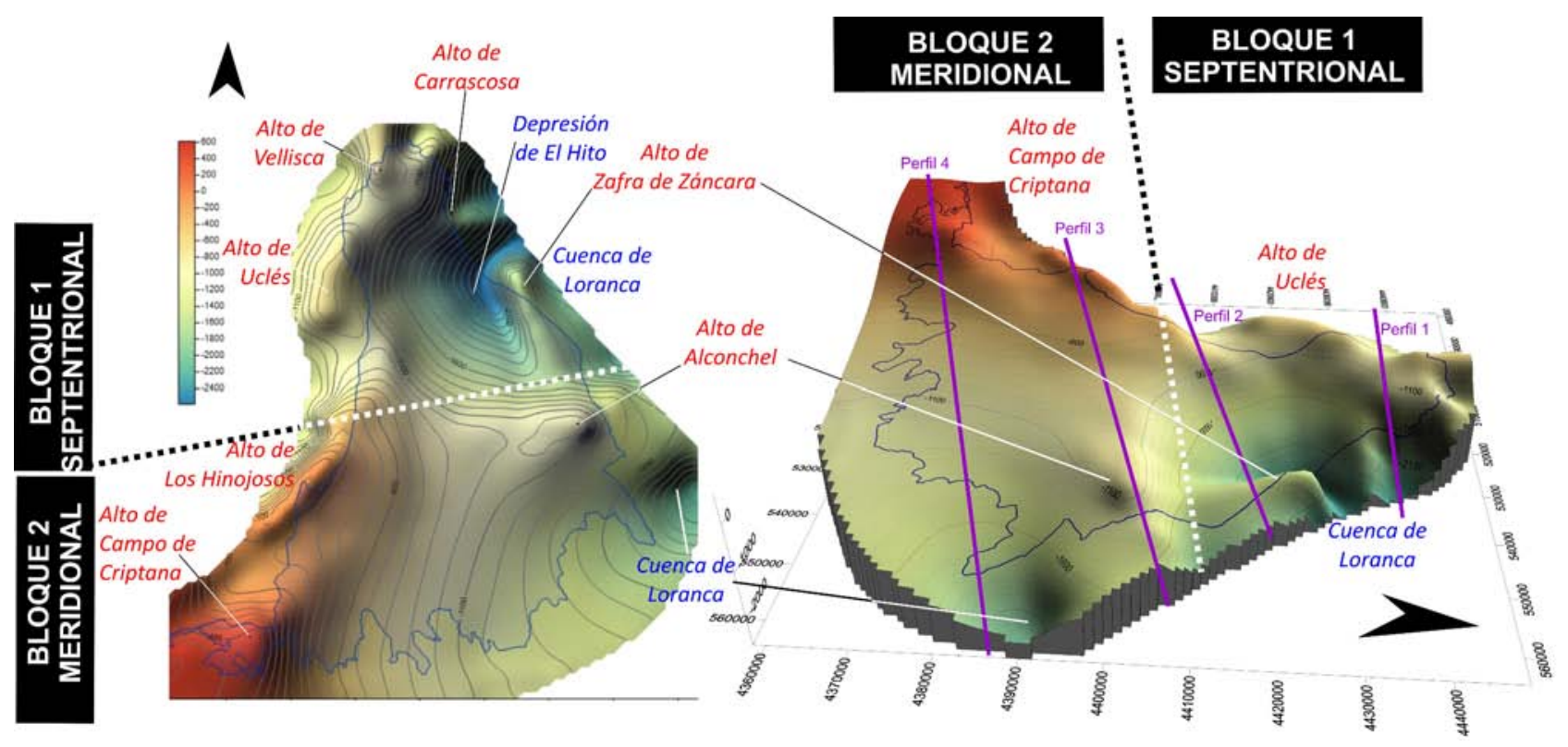

Figura 12. Dos vistas con diferente orientación de la modelización 3D del techo del basamento Varisco, e identificación de las principales estructuras (modelo 3D: M. Rajado).

Figure 12. Two views with different orientation of the 3D basement model, and main structural unit identification (3D model: M. Rajado).

El conjunto del altiplano de Haro y alto de Alconchel presentan, en planta, una morfología de cuña que separa las depresiones de El Hito, al norte del ápice, y de Loranca, al este y sur del mismo.

\section{Resultados: modelo de compartimentación}

La compartimentación hidrogeológica propuesta se basa en la disposición de las unidades cronoestratigráficas jurásica y cretácica que incluyen las formaciones más importantes a nivel de aprovechamiento de recursos hídricos subterráneos por cantidad y calidad de agua (IGME, 2014).

Se obvian los niveles permeables terciarios que rellenan las cuencas y que, aunque constituyen acuíferos locales de importancia moderada, se desconoce su papel en la dinámica hidrogeológica del conjunto de la MASb.

El modelo de compartimentación propuesto se hace a diferentes escalas, desde el nivel regional de la MASb, al nivel más local a escala de afloramiento.

\section{Compartimentación regional: Bloques Septentrional y Meridional}

Se divide la MASb Sierra de Altomira en dos áreas estructurales diferenciadas, los Bloques Septentrional y Meridional, con características estructurales y sedi- mentológicas propias. A su vez, cada bloque queda dividido en diferentes sectores: en el Bloque Septentrional (perfiles 1 y 2 de la Figura 13) se diferencian los sectores I, II y III; en el Bloque Meridional (perfiles 3 y 4 , figura 13) los sectores IV y V.

\section{Bloque Septentrional}

La estructura de la serie mesozoica se caracteriza por el apilamiento, en sentido oeste, de varias escamas cabalgantes. Estas afloran a favor de cabalgamientos de gran salto, cuyo nivel de despegue se encuentra en las facies plásticas del Keuper. La serie mesozoica presenta buzamientos muy verticalizados en los anticlinorios aflorantes. Cada cabalgamiento mayor está asociado a una discontinuidad o escalón en el basamento.

El escalón del basamento existente entre la depresión de El Hito y los altos de Uclés y Vellisca (más de $1.600 \mathrm{~m}$ de salto) tiene una orientación con respecto a la/s dirección/es de esfuerzo prácticamente perpendicular. Consecuentemente, se producen cabalgamientos de gran salto que desconectan la serie mesozoica entre la escama cabalgante y la escama cabalgada (perfil 1, figura 13). En el sector II, el escalón del basamento del alto de Carrascosa da lugar al anticlinal de Carrascosa, así como en el sector III, el alto de Zafra de Záncara da lugar al cabalgamiento que origina el anticlinal homónimo. En el extremo 


\begin{tabular}{|c|c|}
\hline UNIDAD ZÓCALO & DESCRIPCIÓN \\
\hline Alto de Vellisca & Se trata de un bloque elevado ubicado en el extremo noroccidental de la MASb. \\
\hline Alto de Uclés & $\begin{array}{l}\text { Esta elevación se situa en el margen noroccidental de la MASb. Origina junto con el bloque Vellisca } \\
\text { una zona elevada ( }-800 \mathrm{~m} \text { s.n.m.) en la que un umbral de menor cota separa ambos altos. Constituye } \\
\text { un alto estructural con gran salto respecto del bloque denominado El Hito, situado más al este. }\end{array}$ \\
\hline Alto de Carrascosa & $\begin{array}{l}\text { Se sitúa en el margen nororiental de la MASb. Está constituido por un bloque elevado de pequeñas } \\
\text { dimensiones, interpuesto entre las grandes depresiones de El Hito y la Cuenca de Loranca, al este. }\end{array}$ \\
\hline Depresión de El Hito & $\begin{array}{l}\text { Este bloque hundido ocupa la parte central de la mitad norte de la MASb Sierra de Altomira. Origina } \\
\text { la depresión de El Hito, donde el basamento se hunde hasta los }-2.400 \mathrm{~m} \text { s.n.m. }\end{array}$ \\
\hline $\begin{array}{l}\text { Alto de Zafra de } \\
\text { Záncara }\end{array}$ & $\begin{array}{l}\text { Se ubica al noreste de la MASb. Se trata de una elevación (-1.800 m s.n.m.) estrecha y alargada en } \\
\text { forma de apéndice de dirección NNO-SSE que se sitúa bajo la población de Zafra de Záncara. Este } \\
\text { alto relativo se interpone entre los bloques hundidos de El Hito, y el de la cuenca de Loranca, ya fuera } \\
\text { del perímetro de la MASb. }\end{array}$ \\
\hline $\begin{array}{l}\text { Alto de Los } \\
\text { Hinojosos-Campo de } \\
\text { Criptana }\end{array}$ & $\begin{array}{l}\text { Ocupa todo el margen occidental de la mitad meridional de la MASb. Integra los altos relativos de } \\
\text { Los Hinojosos ( }+0 \mathrm{~m} \text { s.n.m.) y el de Campo de Criptana en donde se alcanza la cota máxima de la } \\
\text { MASb ( }+300 \mathrm{~m} \text { s.n.m.). Ambos altos están separados por un corredor de menor cota relativa. }\end{array}$ \\
\hline Altiplano de Haro & $\begin{array}{l}\text { Ocupa toda el área centro oriental de la mitad sur de la MASb. En este amplio sector la superficie del } \\
\text { basamento va hundiéndose progresivamente hacia el este, por lo que crea una especie de altiplano } \\
\text { inclinado que alcanza el limite este de la MASb (-1.100 m s.n.m.). Más al este el basamento se hunde } \\
\text { bruscamente dando lugar a la cuenca de Loranca }(-2.200 \mathrm{~m} \text { s.n.m.). }\end{array}$ \\
\hline Alto de Alconchel & $\begin{array}{l}\text { Ocupa el tercio noreste de la mitad sur de la MASb, bajo la población de Alconchel de la Estrella, } \\
\text { haciendo de limite entre la depresión de El Hito al norte y el altiplano de Haro, al sur. Esta elevación } \\
\text { interrumpe el hundimiento paulatino del basamento hacia el este. }\end{array}$ \\
\hline Cuenca de Loranca & $\begin{array}{l}\text { Gran depresión del basamento configurada por un bloque hundido que da lugar al potente relleno } \\
\text { sedimentario de la cuenca de Loranca. Se localiza en todo el margen oriental de la MASb Sierra de } \\
\text { Altomira, fuera de sus limites. }\end{array}$ \\
\hline
\end{tabular}

Tabla 2. Principales unidades estructurales diferenciadas en el modelo 3D del basamento.

Table 2. Main structural units in the 3D basement model.

oriental el basamento se hunde hasta cotas inferiores a los -2.500 m s.n.m. bajo el relleno sedimentario de la cuenca de Loranca.

Las cuencas piggy-back de rellenos cenozoicos asociadas, tienen un espesor reducido en el oeste por la imbricación de varias escamas. Por el contrario, la potencia de estas es mucho mayor en el sector oriental, en donde se rellenan a favor de bloques hundidos y no existe limitación espacial con la escama tectónica contigua.

Los ríos principales del Bloque Septentrional (Bedija, Riansares y Gigüela) discurren en sentido SO hacia las MASb Lillo-Quintanar y Consuegra-Villacañas, salvo el río Záncara que, una vez atravesado el aflora- miento mesozoico de Zafra de Záncara toma dirección sur, hacia el Bloque Meridional (Figura 4).

\section{Bloque Meridional}

La diferencia estructural de la serie sedimentaria mesozoica en este Bloque, con respecto al anterior, es notable (Figura 13). En el Bloque Septentrional la estructura presenta una arquitectura más segmentada, con una tasa de acortamiento mayor a favor de cabalgamientos de gran salto, mientras que en el Bloque Meridional los cabalgamientos muestran un desplazamiento significativamente menor, y una tasa 


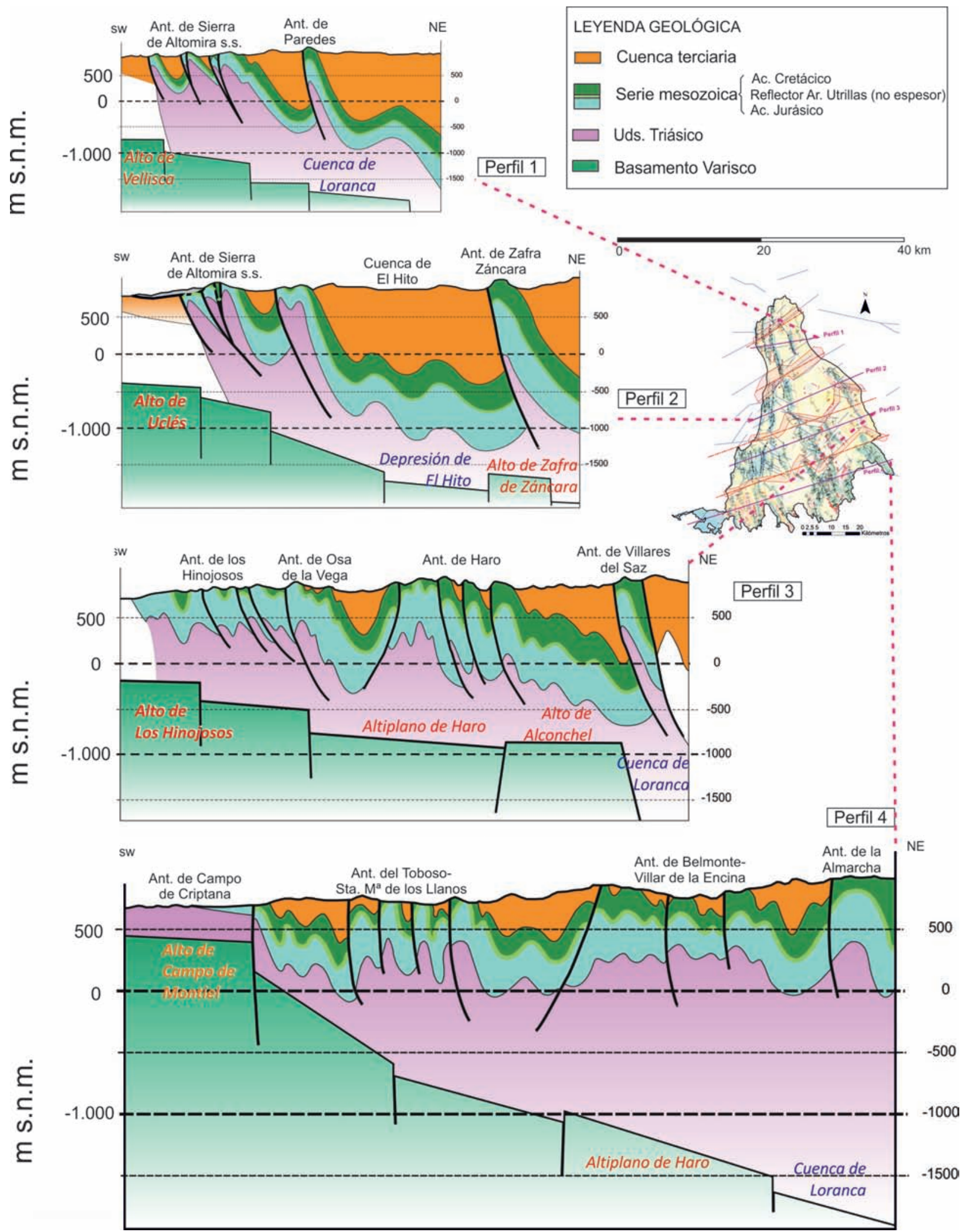

Figura 13. Cortes geológico-estructurales de la MASb Sierra de Altomira. Elaborados a partir de los mapas de isobatas de IGME e INYPSA, 2010.

Figure 13. Geological-structural cross sections of Sierra de Altomira GWB. Made from the isobaths maps included in IGME and INYPSA, 2010. 


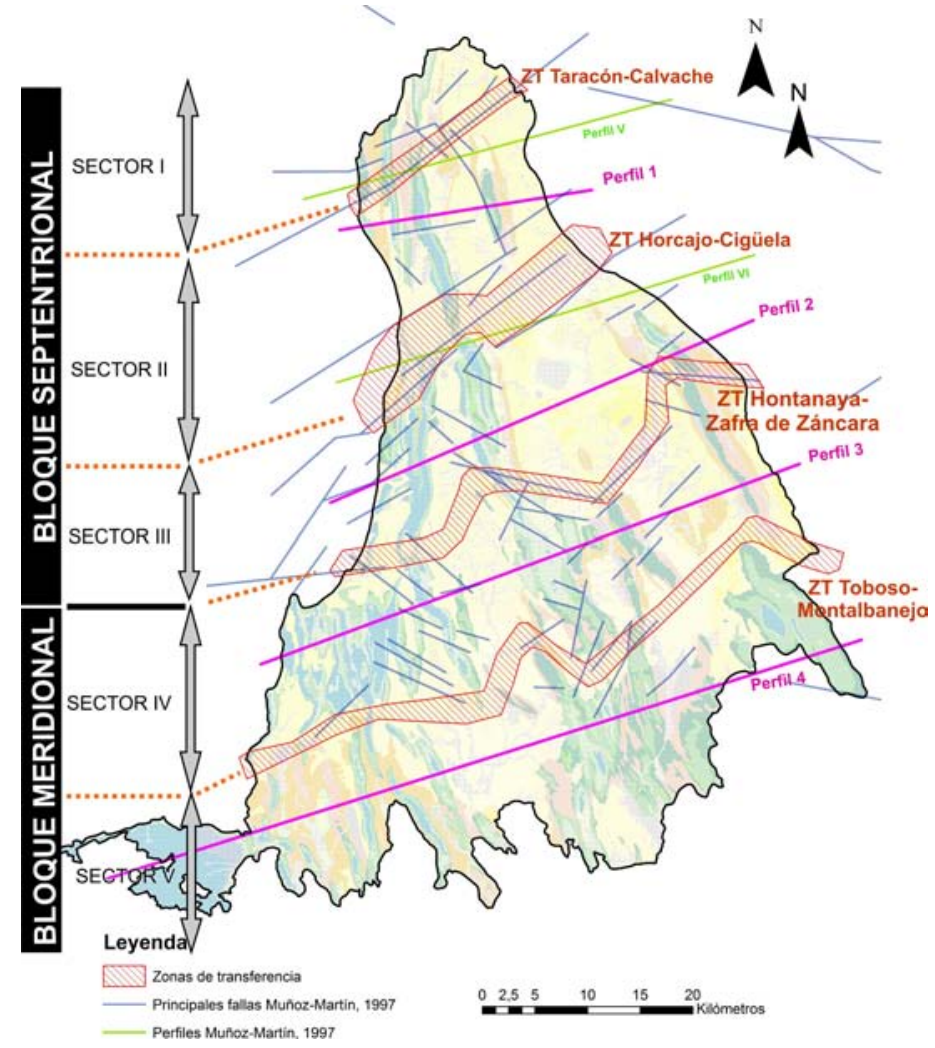

Figura 14. Sectorización estructural de la MASb Sierra de Altomira (sectores I a V) e identificación de las 4 zonas de transferencia (ZT). Posición de los perfiles geológicos V y VI (Muñoz-Martín, 1997) y de los perfiles 1 a 4 de la figura 12.

Figure 14. Structural division of the Sierra de Altomira GWB (sectors I to V) and 4 transfer zones (ZT). Location of the 1 to 4 geological cross sections (Fig. 12,) and V \& VI from (Muñoz-Martín, 1997).

de acortamiento también menor (Muñoz-Martín, 1997). La estructura general resultante se encuentra más replegada en respuesta a los esfuerzos compresivos que no han desconectado la serie a favor de cabalgamientos.

En este Bloque la desconexión tectónica de los niveles mesozoicos no es efectiva. En los perfiles 3 y 4 de la figura 13, se observa como las series mesozoicas no desconectan completamente en la mayoría de los casos ya que los saltos de cabalgamiento no son suficientemente grandes. Los niveles impermeables del Triásico no ascienden hasta posiciones estructurales en las que constituyen una barrera hidrogeológica entre ambos márgenes del cabalgamiento, como sí ocurre en el Bloque Septentrional (perfiles 1 y 2, figura 13).

El zócalo del Bloque Meridional se encuentra en una posición sobreelevada con respecto al Septentrional (altos de Campo de Criptana y de los Hinojosos, y altiplano de Haro), por lo que la serie sedimentaria suprayacente (mesozoica y cenozoica) tendrá una posición relativa igualmente elevada. Esta sería la causa por la cual la tasa de afloramiento mesozoico en la mitad sur es significativamente mayor que en la norte.

En el basamento, el conjunto estructural del altiplano de Haro y el alto de Alconchel presentan, en planta, forma de cuña cuyo vértice agudo lo conforma el alto de Alconchel (Figura 12). Con respecto a las direcciones principales de esfuerzos compresivos NO-SE y E-O, el vértice supone una discontinuidad transversal (ortogonal) a los esfuerzos, mientras que las rampas laterales suponen discontinuidades oblicuas. La respuesta de la cobertera a esta morfología en cuña del zócalo se traduce en cabalgamientos con desplazamiento mínimo, numerosos pliegues de buzamientos más suavizados y desplazamiento diferencial a favor de fallas o transfers oblicuos en las rampas laterales. En el vértice de Alconchel, dada la ortogonalidad puntual de la discontinuidad, se genera un cabalgamiento de mayor recorrido que en el conjunto del Bloque Meridional, que en superficie da origen al anticlinal de Villares del Saz. La desconexión hidrogeológica de la serie mesozoica a ambos lados de la traza de este cabalgamiento es completa (perfil 3, Figura 14). 
La mitad sur del Bloque Meridional (límite sur de la $\mathrm{MASb})$ se ha diferenciado como el sector morfoestructural V. Se caracteriza por presentar las estructuras compresivas de menor deformación de toda la MASb. En el perfil 4 (Figura 13) se puede observar una relativa continuidad estructural de las unidades sedimentarias mesozoicas en sentido E-O, únicamente interrumpida por cabalgamientos de mínimo recorrido.

Por su parte, los ríos del bloque meridional fluyen en sentido norte-sur, paralelos a la dirección estructural de los afloramientos mesozoicos, hacia las MASb Mancha Occidental II y Rus-Valdelobos (Figura 4).

\section{Compartimentación a escala intermedia: sectores I a V}

En la Tabla 3 se incluyen las características más relevantes de cada uno de los sectores que constituyen la base del modelo de compartimentación resultante.
Los límites de cada sector quedan establecidos por los propios del contorno de la MASb Sierra de Altomira, además de las cuatro divisorias que separan los 5 bloques definidos. Estas divisorias internas se han hecho coincidir con zonas de transferencia tectónica o accidentes oblicuos (Sánchez-Soria, 1973; MuñozMartín, 1997) que constituyen las principales fallas transversales a las estructuras sedimentarias (Figura 14). De aquí en adelante, estas zonas de transferencia $Z T$ constituirán divisorias entre bloques en los que la serie mesozoica presenta unas características estructurales y un grado de acortamiento diferentes.

\section{Compartimentación a escala local: Unidad Hidrogeológica Básica}

En la propuesta de compartimentación a las escalas regional e intermedia (divisorias $\mathrm{E}-\mathrm{O}$, en sentido trans-

\begin{tabular}{|c|c|c|c|c|c|c|}
\hline & SECTOR & $\begin{array}{c}\text { ANCHURA } \\
\text { MASb } \\
(\mathrm{km})\end{array}$ & $\begin{array}{l}\text { SUPERF } \\
\left(\mathrm{km}^{2}\right)\end{array}$ & DIRECCIÓN ESTRUCT. & LIMITES & FUNCIONAMIENTO/DESCRIPCIÓN \\
\hline \multirow{3}{*}{ 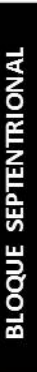 } & $\begin{array}{c}\text { Sector } \\
1\end{array}$ & 17 & 120 & $\mathrm{~N}-\mathrm{S}$ & $\begin{array}{l}\text { Demarcación delTajo: } \\
\text {-MASb Entrepeñas al NO } \\
\text {-Cuenca de Lorancaal NE } \\
\text { Demarcación del Guadiana: } \\
\text {-MASb Lillo-Quintanar alO }\end{array}$ & $\begin{array}{l}\text { Afloramientos mesozoicos a favor de anticlinales apilados de buzamiento muy verticalizado con ligera vergencia al oeste. Sector con mayor acortamiento } \\
\text { tectónico dentro de la MASb Sierra de Altomira (Muñoz-Martin 1997). } \\
\text { Práctica desconexión hidrogeológica en sentido este-oeste (entre las diferentes escamas), y mayor conectividad relativa en sentido N-S. La circulación de flujo } \\
\text { subterránea se produciria mayoritariamente en este sentido (N-S) dentro de cada escama, y dirigida hacia las zonas de descarga: cauce del rio Riansares en } \\
\text { superfície, y la ZTT en sentidoSO, en profundidad }\end{array}$ \\
\hline & \multicolumn{3}{|c|}{$\begin{array}{l}\text { ZONADETRANSFERENCIA } \\
\text { TARANCÓN-CAIVACHEZIT }\end{array}$} & NE-SO & & $\begin{array}{l}\text { Integrada por las fallas de Tarancón y Calvache. Zona de debilidad que aprovecha el rio Riansares para atravesar los afloramientos mesozoicos en sentido NE- } \\
\text { so. }\end{array}$ \\
\hline & $\begin{array}{c}\text { Sector } \\
\text { II }\end{array}$ & 17 & 270 & $\mathrm{~N}-\mathrm{S}$ & $\begin{array}{l}\text {-MASb Lillo-Quintanar alo } \\
\text {-MASb la Obispalía al E }\end{array}$ & $\begin{array}{l}\text { Afloramientos mesozoicos a favor de anticlinales de buzamiento verticalizado con ligera vergencia al oeste. Sector con mayor acortamiento tectónico dentro de } \\
\text { la MASb Sierra de Altomira (Muñoz-Martin 1997), aunquemenor que en el sector Anterior. } \\
\text { Práctica desconexión hidrogeológica en sentido este-oeste (entre las diferentes escamas), y mayor conectividadrelativa en sentidoN-S. } \\
\text { El patrón de circulación subterránea: recarga en las zonas de afloramiento me sozoico, más elevadas, y circulación subterránea hacia sus sectores de descarga, } \\
\text { preferentemente enlos márgenesnorte y sur de cada subsector, esto esla zona de transferencia ZTH al sur, yla ZTT, al norte. }\end{array}$ \\
\hline \multicolumn{4}{|c|}{$\begin{array}{l}\text { ZONADETRANSFERENCIA } \\
\text { HORCANO-GIGUEELAZTH }\end{array}$} & NE-SO & & $\begin{array}{l}\text { Integrada por las fallas de Horcajo, Segóbriga y Gigüela. Zona de debilidad que aprovechan los rios Gigüela y Bedija para atravesar los afloramientos } \\
\text { mesozoicos en sentidoNE-SO. }\end{array}$ \\
\hline \multirow{5}{*}{ 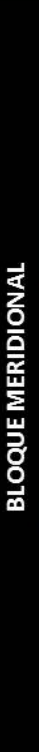 } & $\begin{array}{c}\text { Sector } \\
\text { III }\end{array}$ & 34 & 600 & \begin{tabular}{l|} 
Variable de O a E: \\
- N-S rama Almenara \\
- NNO-SSE rama \\
Villarejo \\
- NO-SEZafra de \\
Záncara
\end{tabular} & $\begin{array}{l}\text {-MASb Lillo-Quintanar alO } \\
\text {-MASb la Obispalía alE }\end{array}$ & $\begin{array}{l}\text { Afloramientos mesozoicos a favor de anticlinales de buzamiento verticalizado con ligera vergencia al oeste. Sector con mayor acortamiento tectónico dentro de } \\
\text { la MASb Sierra de Altomira (Muñoz-Martin 1997), aunquemenor que en los sectores Anteriores. } \\
\text { Práctica desconexión hidrogeológica en sentido este-oeste (entre las diferentes escamas), y mayor conectividad relativa en sentido N-S. En el anticlinal de } \\
\text { Zafra de Záncara, (afloramiento de morfologia de aislada), indicaria una desconexión parcial en el sentido de la máxima compresión E-O, desconexión que } \\
\text { seria menos efectivaal alejarnos del afloramiento, en sentidonorte y sur. } \\
\text { El patrón de circulación subterránea: recarga en las zonas de afloramiento mesozoico, más elevadas, y circulación subterránea hacia sus sectores de descarga, } \\
\text { preferentemente enel margen norte del subsector. }\end{array}$ \\
\hline & \multicolumn{3}{|c|}{$\begin{array}{l}\text { ZONADE TRANSFERENCIA } \\
\text { HONTANAYAZZARA DE } \\
\text { ZÁNCARAZIZ }\end{array}$} & $\begin{array}{c}\text { Grupo de fallas. Dirección } \\
\text { del conjunto NE-SO }\end{array}$ & & Familia de fallas NE-SO a ONO-ESE que, en su conjunto, actuarian como zona de tranferencia estructural-hidrogeológicaen direcciónNE-SO \\
\hline & $\begin{array}{c}\text { Sector } \\
\text { IV }\end{array}$ & 50 & 710 & $\begin{array}{l}\text { Variable de O a E: } \\
\text { - N-S Los Hinojosos } \\
\text { - NNO-SSE comarca de } \\
\text { Haro } \\
\text { - NO-SEZafra de } \\
\text { Záncara }\end{array}$ & $\begin{array}{l}\text {-MASb Consuegra-Villacañasy } \\
\text { mínimamente la de Lillo- } \\
\text { Quintanar, por el O } \\
\text {-MASb de la Serranía de Cuenca } \\
\text { (D.H. Júcar) al E }\end{array}$ & $\begin{array}{l}\text { Estructuralmente, de oeste a este, se diferencia el sector occidental (Los Hinojosos) caracterizado por el apilamiento de anticlinales jurásicos de dirección N-S a } \\
\text { NO-SE cabalgados entre si en sentido oeste; el bloque anticlinorio de afloramientos mesozoicos (mayoritariamente cretácicos) de Tresjuncos-Alconchel, con } \\
\text { cabalgamientos NNO-SSE de menor salto que en los sectores septentrionales; por último, el anticlinorio mesozoico de Villares del Saz, constituido por un } \\
\text { bloque anticlinal, tectónicamente elevado y direcciónNO-SE, de gran extensión superficial. } \\
\text { Hidrogeológicamente se trata de un bloque tectónicamente elevado por lo que el flujo de agua se produciria hacia el notte y sur (ZIZ y ZTM respectivamente), } \\
\text { hacia el este mediante tranferencia al terciario, y en menor medida hacia el oeste. La conexión hidrogeológica es mayor que en los sectores anteriores. }\end{array}$ \\
\hline & \multicolumn{3}{|c|}{$\begin{array}{c}\text { ZONA DE TRANSFERENCIA } \\
\text { TOBOSO-MONTALBANEOZTM }\end{array}$} & $\begin{array}{c}\begin{array}{c}\text { Grupo de fallas. Dirección } \\
\text { del conjuntoNE-SO }\end{array} \\
\end{array}$ & & Familia de fallas NE-SO a ONO-ESE que, en su conjunto, actuarian como zona de tranferencia estructural-hidrogeológica en direcciónNE-SO \\
\hline & $\begin{array}{c}\text { Sector } \\
\mathrm{v}\end{array}$ & 70 & 880 & $\begin{array}{l}\text { Variable de O a E: } \\
\text { - N-S Campo de } \\
\text { Criptana } \\
\text { - NNO-SSE comarca de } \\
\text { Haro } \\
\text { - NO-SE Castillo de } \\
\text { Garcimuñoz }\end{array}$ & $\begin{array}{l}\text {-MASb Consuegra-Villacañas, por } \\
\text { el O } \\
\text {-MASb de la Serraníade Cuenca } \\
\text { (D.H. Júcar) al E } \\
\text {-Llanura manchega, al sur(MASb } \\
\text { Mancha Occidental Ily Rus- } \\
\text { Valdelobos) }\end{array}$ & $\begin{array}{l}\text { Estructuralmente, de oeste a este, se diferencia el sector occidental (Toboso-Sta. Maria de los Llanos) caracterizado por el afloramiento lineal las chamelas de } \\
\text { anticlinales jurásicos de dirección N-S a NO-SE, de plegamiento suave y mayor contimuidad estructural; el bloque anticlinorio de afloramientos mesozoicos de } \\
\text { la comarca de Haro, con cabalgamientos NNO-SSE de menor salto que en los sectores septentrionales; por último, el anticlinorio mesozoico de Castillo de } \\
\text { Garcimuñoz, constituidopor unbloque antícinal, tectónicamente elevadoy dirección NO-SE, de gran extensión superficial. } \\
\text { Hidrogeológicamente se trata de un bloque tectónicamente más bajo que el bloque IV, por lo que se convertiria en receptor de agua subterránea desde este a } \\
\text { través de la ZIM. La serie mesozoica presenta una contirnidad lateral mayor que en el resto de los sectores de la MASb. El flujo subterráneo en los niveles } \\
\text { mesozoicostendria componentes sur y suroesteprincipalmente (hacia la Llanura Manchega). }\end{array}$ \\
\hline
\end{tabular}

Tabla 3. Descripción de los diferentes sectores en los que se ha estructurado la MASb Sierra de Altomira.

Table 3. Structural unit description of the Sierra de Altomira GWB. 
versal a las estructuras), que dan lugar a los dos bloques estructurales a escala regional, e integrados a su vez por los sectores I a V (I a III el bloque septentrional, IV y $\mathrm{V}$ el meridional), a escala intermedia, no se integran las divisorias hidrogeológicas representadas en la figura 15, identificadas a partir de criterios hidrogeológicos (IGME, 2017 a y b), y estructurales (Figura 13). Se define así una compartimentación, a escala local, que integra todas las divisorias.

Se define así la Unidad Hidrogeológica Básica $(U H B)$, que constituye la unidad estructural mínima e indivisible. La componen las tres unidades tectonosedimentarias ya descritas en el marco tectónico de la Sierra de Altomira (basamento-tegumento, nivel de despegue triásico y cobertera sedimentaria). En sentido este-oeste, cada una de las escamas tectónicas existentes compuesta por un pliegue de flexión de falla en su extremo occidental, y una cuenca sedimentaria adosada en la zona de traspaís, hacia el este, constituyen una UHB. Sus márgenes norte y sur se identifican con las zonas de transferencia tectónica que delimitan los 5 sectores entre sí, además de los límites norte y sur de la masa de agua Sierra de Altomira (Figura 16).

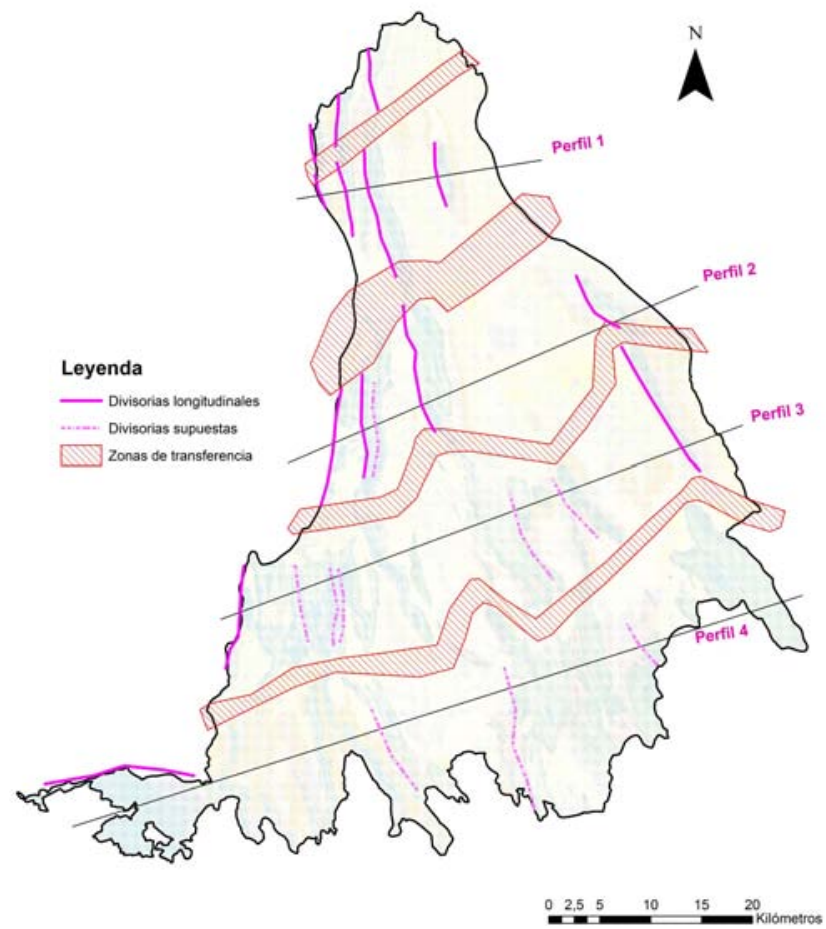

Figura 15. Divisorias longitudinales seguras y supuestas trazadas a partir de la interpretación de la estructura del basamento de la MASb Sierra de Altomira.

Figure 15. Sure and supposed longitudinal dividing lines drawn from the interpretation of the basement structure of the Sierra de Altomira GWB.
Por tanto, cada sector diferenciado a escala intermedia (sectores I a V) estaría compuesto por diferentes UHBs. Las UHBs integrantes de un mismo sector, o las de un sector con las del contiguo, se relacionan hidrogeológicamente entre sí de forma diferente en función de la zona considerada. En la figura 16 se representa un modelo 3D teórico de UHB, en la que se intenta aunar el máximo de información geológica-estructural que tiene influencia en el funcionamiento hidrogeológico del bloque. La relación entre las diferentes UHBs determinará, en su conjunto, el modelo hidrogeológico conceptual de la MASb.

El modelo hidrogeológico conceptual, para una UHB cualquiera, se describe a partir de los ítems identificados en la figura 16: la recarga de los acuíferos mesozoicos se produce por infiltración directa del agua de lluvia a través de los materiales permeables mesozoicos aflorantes (ítem a), de forma individual para cada una de las unidades acuíferas jurásica y cretácica. También contribuyen a la recarga los aportes de los ríos (tramos influentes) que atraviesan las unidades permeables, coincidentes normalmente con zonas de transferencia hidrogeológica (ítem c); el agua infiltrada alcanza la zona saturada a través de la red de karstificación/fracturación de los materiales carbonatados jurásicos y cretácicos (ítem b).

Los materiales mesozoicos aflorantes se hunden bajo la cuenca sedimentaria terciaria, al este, hasta alcanzar su máxima profundidad en el límite con la UHB contigua. Los acuíferos jurásico y cretácico pasan, de régimen libre en los relieves aflorantes, a confinado, bajo la cuenca. En la medida en que la cota piezométrica mesozoica sea superior a la de los niveles terciarios suprayacentes, se producirá una lenta, pero constante, recarga vertical a través de la base de los materiales terciarios (ítem c).

El agua de recarga que alcanza la zona saturada genera un ascenso piezométrico en el tramo de acuífero libre y produce un incremento de la presión hidrostática en los tramos confinados; la dirección de avance del flujo subterráneo se produce, a escala de afloramiento, de forma radial en sentido norte y sur, dentro de la misma formación acuífera (ítem d), y en sentido este, en forma de transferencia lateral a los niveles permeables del relleno terciario (ítem e). La conexión hidráulica de los afloramientos permeables mesozoicos (escama cabalgante), con los acuíferos de la UHB situada al oeste (escama cabalgada), es inexistente en la mitad septentrional de la MASb, y difícil, en términos relativos, en la mitad meridional, aunque las posibilidades son mayores cuanto más al sur de la MASb.

El avance del flujo subterráneo en los sentidos norte y sur, dentro de una UHB, alcanza sus límites 


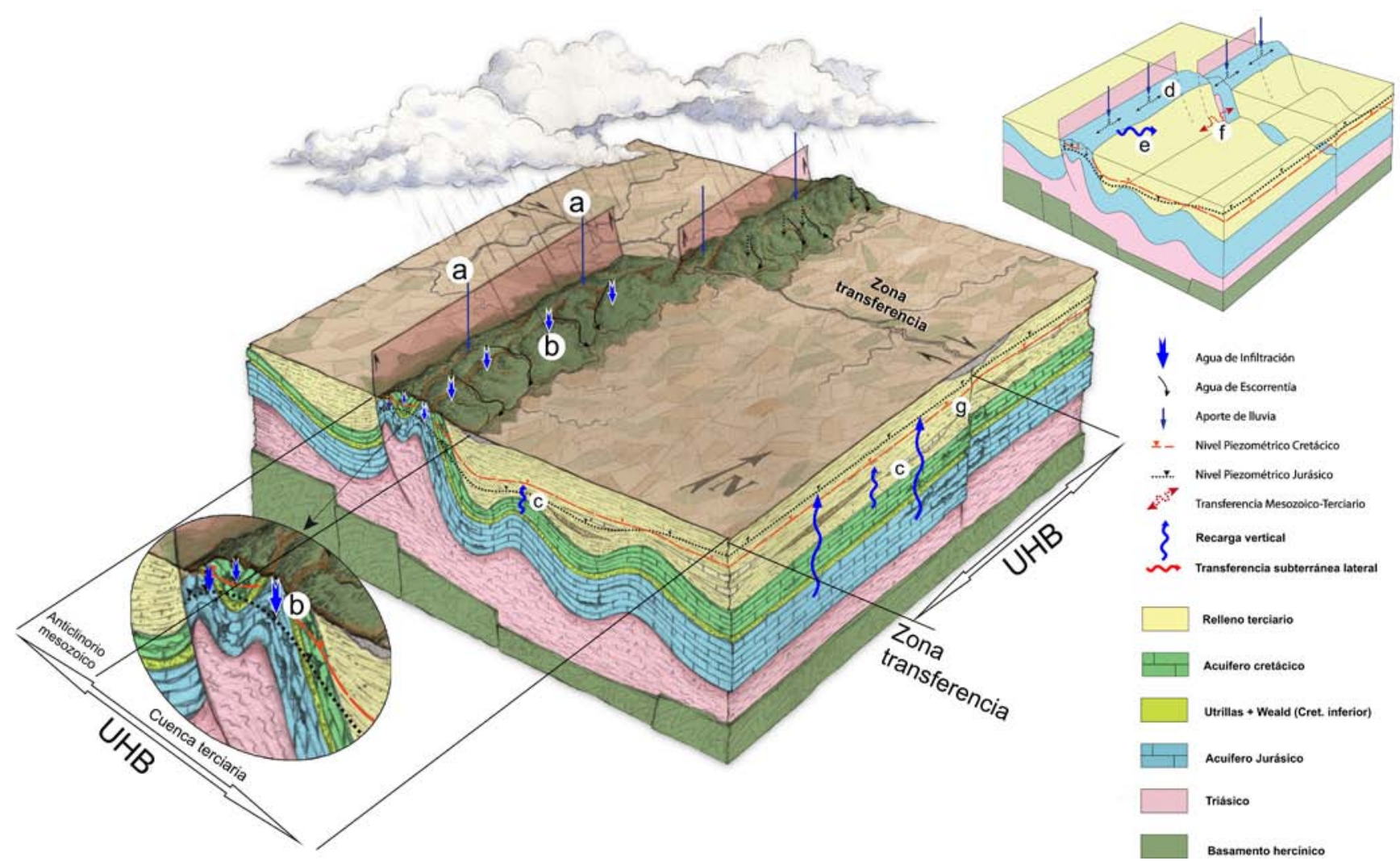

Figura 16. Bloque diagrama representativo de la Unidad Hidrogeológica Básica (UHB) (ilustración: M. Rajado).

Figure 16. Basic Hydrogeological Unit (BHU) model (picture: M.Rajado).

situados en zonas de transferencia tectónica (a la postre, definidas como zonas de transferencia hidrogeológica). En estas zonas se produce transferencia hidráulica entre las formaciones permeables puestas en contacto (mesozoico-mesozoico o mesozoico-terciario) de diferentes sectores, desde la de mayor potencial hidráulico a la de menor $\mathrm{y}$, de forma selectiva, hacia las formaciones más transmisivas (ítem f). Además, estas zonas de transferencia son zonas de debilidad a través de las cuales los ríos se encajan y atraviesan los afloramientos mesozoicos, por lo que, normalmente, actúan como zonas de conexión ríoacuífero (ítem g).

Consecuentemente las zonas de transferencia tectónica articulan, en definitiva, el modelo hidrogeológico conceptual de la MASb, relacionando los diferentes sectores tectónicos.

\section{Resumen}

El modelo estructural de la formación y evolución tectónica de la Sierra de Altomira tiene gran relevancia a la hora de determinar una posible compartimentación hidrogeológica de la MASb 041.001 Sierra de Altomira.

Este modelo relaciona las zonas de plegamiento y cabalgamiento que dan lugar a los diferentes cinturones de pliegues, con discontinuidades en el basamento profundo reactivadas durante la orogenia alpina. Estas discontinuidades actuarían como centros de nucleación de los anticlinorios que componen la Sierra de Altomira.

Se trata de un modelo tectónico de "piel fina" (thin-skinned), con nivel de despegue en las facies plásticas del Keuper. Según este modelo, el basamento no se vería implicado en el acortamiento de la serie sedimentaria, sin embargo se pone de manifiesto que la morfología del mismo (discontinuidades y su orientación) condiciona el grado de desconexión tectónica, e hidrogeológica en consecuencia, de la serie sedimentaria mesozoica.

Los esfuerzos perpendiculares a las discontinuidades del basamento producen cabalgamientos de gran salto que dan lugar a la desconexión tectónica de la serie permeable mesozoica. En cambio, si los esfuerzos compresivos tienen una dirección oblicua a las discontinuidades se produce un mayor repliegue de 
Jesús del Pozo Tejado, et al., 2019. Propuesta de compartimentación estructural en la... Boletín Geológico y Minero, 130 (2): $317-340$

la serie sedimentaria y cabalgamientos menores y no se llega a producir una total desconexión tectónicahidrogeológica.

En la MASb Sierra de Altomira se ha realizado una compartimentación a escala regional de MASb en la que se han diferenciado dos bloques: el Septentrional, caracterizado por cabalgamientos de gran salto que producen un importante acortamiento tectónico; pliegues de propagación de falla con buzamientos muy verticalizados y vergencia al oeste que desconectan completamente la serie mesozoica; y el Meridional, con una estructura mucho más ondulada y replegada, buzamientos más suavizados; los cabalgamientos presentan un salto menor y el acortamiento es mínimo. La desconexión de la serie mesozoica, en la mayoría de los casos, no es completa.

Dentro de estos bloques, a escala intermedia, se han diferenciado los sectores I a V, de norte a sur (Ios sectores I, II, y III dentro del Bloque Septentrional, y los sectores IV y $\mathrm{V}$ en el Bloque Meridional). La divisoria entre sectores se hace coincidir con zonas de transferencia tectónica (ZT) que, a la postre, se han revelado como zonas de transferencia hidrogeológica (entre diferentes acuíferos de un mismo sector o de sectores vecinos, o bien con los cauces superficiales).

Para describir de forma detallada el modelo hidrogeológico conceptual básico se ha definido la Unidad Hidrogeológica Básica (UHB) a escala local, como elemento base de la compartimentación de $3^{\circ}$ orden. La MASb Sierra de Altomira queda así integrada por diferentes UHB s, con una arquitectura de la serie sedimentaria mesozoica más o menos fracturada y/o plegada, y dimensiones diferentes dependiendo del sector, pero cuyo funcionamiento hidrogeológico se reduce a las siguientes fases:

La recarga se produce mayoritariamente por infiltración del agua de lluvia en los afloramientos mesozoicos y por aportes de los ríos que atraviesan los mismos (tramos influentes).

El agua alcanza la zona saturada del acuífero y se desplaza de forma radial, salvo por el margen occidental de la UHB, limitado por el cabalgamiento asociado al mismo.

El flujo avanza en sentido norte y sur, hasta alcanzar las zonas de transferencia tectónica/hidrogeológica. En estas zonas el flujo subterráneo se transfiere hacia otras UHB o bien alcanza la superficie en forma de aportes a los cauces superficiales (tramos efluentes).

Los acuíferos mesozoicos pasan de régimen libre, en las zonas de afloramiento, a régimen confinado bajo las cuencas sedimentarias terciarias. El estado de confinamiento favorece un flujo subterráneo ascendente de recarga, hacia los niveles terciarios suprayacentes.

\section{Conclusiones}

La estructura interna de la MASb Sierra de Altomira es consecuencia de una tectónica de formación compleja. Pese a que el basamento Varisco no se ve implicado en el modelo de deformación de la Sierra de Altomira (modelo thin-skinned), su morfología ha condicionado la estructura de la cobertera resultante en la que se basa la propuesta de compartimentación tectónicahidrogeológica de la MASb 041.001 Sierra de Altomira.

El análisis del modelo estructural de la Sierra de Altomira ha permitido identificar diferentes zonas, en las que la propia estructura condiciona el comportamiento hidrogeológico local. Se propone una compartimentación a tres niveles:

A escala regional de MASb se han diferenciado dos grandes bloques:

Bloque Septentrional, en el que la compartimentación hidrogeológica a favor de cabalgamientos, en sentido N-S, es muy efectiva.

Bloque Meridional, en el que la compartimentación hidrogeológica no es tan efectiva, y las probabilidades de continuidad hidrogeológica en sentido este-oeste aumentan hacia su extremo sur.

A una escala intermedia, los bloques anteriores integran diferentes sectores definidos a partir de las características morfoestructurales de la serie sedimentaria mesozoica (sectores I a V de norte a sur) articulados hidrogeológicamente a través de las zonas de transferencia tectónica/hidrogeológica.

Finalmente, a escala local, se han definido las Unidades Hidrogeológicas Básicas UHB, como la unidad de división mínima, en las que se pueden definir con mayor claridad todos los componentes del modelo hidrogeológico conceptual.

El modelo de compartimentación resultante de la MASb Sierra de Altomira pone en cuarentena la idea de una supuesta continuidad hidráulica de los acuíferos presentes en la misma a lo largo de toda su extensión. La división de la actual MASb en sectores acuíferos independientes constituidos por una única UHB, o la agrupación de varias de estas si se determina que tienen continuidad hidrogeológica proba$\mathrm{da}$, requiere de un estudio a mayor escala.

\section{Agradecimientos}

El presente artículo recoge los trabajos realizados dentro de la "Fase $2^{a}$ del Convenio específico de Colaboración entre la Comunidad de Usuarios del Acuífero 19 Sierra de Altomira y el Instituto Geológico y Minero de España para el apoyo técnico en infraestructura hidrogeológica y aguas subterráneas 2016- 
2018" relativos al estudio e interpretación de la estructura interna de la Sierra de Altomira y sus repercusiones en la hidrodinámica general y local de los acuíferos que la integran.

Para esta labor se ha contado con la inestimable ayuda de los propios usuarios de la Comunidad de Usuarios del Acuífero 19 Sierra de Altomira, encabezados por su presidente D. Rafael Rodrigo Medina, y el personal administrativo y técnico a su cargo, sin cuya colaboración no habría sido posible la toma y recopilación de datos ni el acceso a muchos de los puntos de observación y medida.

Además, se ha contado en todo momento con la colaboración de todos los ayuntamientos incluidos en la MASb Sierra de Altomira, tanto a nivel de personal como de medios técnicos, operarios de empresas de gestión de aguas municipales, y usuarios particulares, que nos facilitaron el acceso a captaciones municipales y pozos privados para la realización de observaciones de control hidrogeológico.

\section{Referencias}

Álvaro, M. y Capote, R. 1973. Las estructuras menores de las calizas jurásicas en un sinclinal de la Sierra de Altomira (Cuenca, España). Estudios geológicos, 46, 241-247.

Biete, C., Roca, E., Hernaiz-Huerta, P.P. 2012. The alpine structure of the basement beneath the southern Loranca basin and its influence in the thin-skinned contractional deformation of the overlying Mesozoic and Cenozoic cover. Geotemas 13-173.

BOE-A-1988-20883. 1988. Real Decreto 927/1988, de 29 de julio, por el que se aprueba el Reglamento de la Administración Pública del agua y de la planificación hidrológica, en desarrollo de los Títulos II y III de la Ley de Aguas.

BOE-A-2013-5318. 2013. Real Decreto 354/2013, de 17 de mayo, por el que se aprueba el Plan Hidrológico de la parte española de la Demarcación Hidrográfica del Guadiana.

Capote, R., Muñoz, J.E., Simón, J.L., Liesa, C.L., Arlegui, L.E. 2002. Alpine tectonics I: the Alpine system north of the Betic Cordillera. En Gibbons, W., Moreno, T. (Eds) Geology of Spain. Geological Society, London, 385-397.

Directiva 2000/60/CE del Parlamento Europeo y del Consejo de 23 de octubre de 2000 por la que se establece un marco comunitario de actuación en el ámbito de la política de aguas.

Guimerà, J. 2004. Cadenas con cobertera: las cadenas Ibérica y Costero Catalana. En Vera, J.A. (ed.), Geología de España. Sociedad Geológica de España e Instituto Geológico y Minero de España, Madrid, 602-616.

Guimerà, J. 2013. Estructura y evolución tectónica de la Cadena Ibérica. En Simón, J.L. y Liesa C.L. (ed.), XLVII Curso de geología práctica: la orogenia alpina de la Cordillera Ibérica. Departamento de Ciencias de laTierra de la Universidad de Zaragoza, Teruel, 1-9.
Guimerà, J. y Álvaro, M. 1990. Structure et evolution de la compresion alpine dans la chaine lberique et la chaine Cotiere Catalane (Spagne). Bulletin de la Soiciete Geologique de France, 2: 339-348.

IGME. 1985. Síntesis hidrogeológica de Castilla-La Mancha. Colección informes. Madrid, 86 págs.

IGME. 2009. Mejora del conocimiento de las MASb Sierra de Altomira (041.001) y Rus-Valdelobos (041.005). Convenio de colaboración entre el Instituto Geológico y Minero de España (IGME) y la Confederación Hidrográfica del Guadiana (CHG).Informe inédito. Centro de documentación del IGME, Madrid.

IGME. 2011. Actualización del conocimiento hidrogeológico de la masa de agua subterránea Sierra de Altomira (041.001). Convenio de colaboración entre la Excma. Diputación de Cuenca y el Instituto Geológico y Minero de España para la mejora del conocimiento hidrogeológico. Centro de documentación del IGME, Madrid, 127 págs. + anejos.

IGME. 2012. Informe de evolución piezométrica de la masa de agua subterránea Sierra de Altomira (041.001). Años 19822012. Diciembre de 2012. Convenio específico de colaboración entre la Comunidad de Usuarios del Acuífero 19 Sierra de Altomira y el IGME, para el apoyo técnico en infraestructura hidrogeológica $y$ aguas subterráneas. 2012-2015. Documento interno, 34 págs. + anejos.

IGME. 2013. $3^{\circ}$ Informe de evolución piezométrica de la masa de agua subterránea Sierra de Altomira (041.001). Años 1982-2013. Diciembre de 2013. Convenio específico de colaboración entre la Comunidad de Usuarios del Acuífero 19 Sierra de Altomira y el IGME, para el apoyo técnico en infraestructura hidrogeológica y aguas subterráneas. 2012-2015. Documento interno, 47 págs. + anejos.

IGME. 2014. Estimación del balance hídrico de la masa de agua subterránea Sierra de Altomira (041.001). Convenio específico de colaboración entre la Comunidad de Usuarios del Acuífero 19 Sierra de Altomira y el IGME, para el apoyo técnico en infraestructura hidrogeológica y aguas subterráneas. 2012-201. Documento interno, 21 págs. + anejos.

IGME. 2015a. Estudio sobre la calidad química de las aguas subterráneas de la Masa de Agua Subterránea "Sierra de Altomira (041.001). Mayo 2015. Convenio específico de colaboración entre la Comunidad de Usuarios del Acuífero 19 Sierra de Altomira y el IGME, para el apoyo técnico en infraestructura hidrogeológica y aguas subterráneas. 2012-2015. Documento interno, 89 págs. + anejos.

IGME. 2015b. Estudio de la evolución piezométrica de la masa de agua subterránea Sierra de Altomira (041.001). Informe recopilatorio años 1982-2015. Diciembre 2015. Convenio específico de colaboración entre la Comunidad de Usuarios del Acuífero 19 Sierra de Altomira y el IGME, para el apoyo técnico en infraestructura hidrogeológica y aguas subterráneas. 20122015. Documento interno, 71 págs. + anejos.

IGME. 2015c. Estudio foronómico recopilatorio de las campañas de medida realizadas en el periodo 2012-2015 en la MASb Sierra de Altomira (041.001). Diciembre de 2015. Convenio específico de colaboración entre la Comunidad de Usuarios del Acuífero 19 Sierra de 
Altomira y el IGME, para el apoyo técnico en infraestructura hidrogeológica y aguas subterráneas. 20122015. Documento interno, 43 págs. + anejos.

IGME. 2016. Informe recopilatorio de los trabajos realizados dentro del Convenio específico de colaboración entre la Comunidad de Usuarios del Acuífero 19 Sierra de Altomira y el Instituto Geológico y Minero de España, para el apoyo técnico en materia de infraestructura hidrogeológica y aguas subterráneas. 2012-2015. Enero 2016. Convenio específico de colaboración entre la Comunidad de Usuarios del Acuífero 19 Sierra de Altomira y el IGME, para el apoyo técnico en infraestructura hidrogeológica y aguas subterráneas. 20162018. Documento interno, 849 págs.

IGME. 2017a. Estudio piezométrico. Campañas de medida 2017 en la MASb "Sierra de Altomira (041.001)" Convenio específico de colaboración entre la Comunidad de Usuarios del Acuífero 19 Sierra de Altomira y el IGME, para el apoyo técnico en infraestructura hidrogeológica y aguas subterráneas. 20162018. Documento interno, 58 págs. + anejos.

IGME. 2017b. Estudio foronómico. Campañas de medida 2017 en la MASb Sierra de Altomira (041.001). Convenio específico de colaboración entre la Comunidad de Usuarios del Acuífero 19 Sierra de Altomira y el IGME, para el apoyo técnico en infraestructura hidrogeológica y aguas subterráneas. 2016-2018. Documento interno, 76 págs. + anejos.

IGME y DGA. 2010. Propuesta de zonificación, basada en criterios geológicos e hidrogeológicos, en la Cuenca Alta del río Guadiana. Actividad 3. Seguimiento y asistencia técnica en el proceso de planificación hidrológica. Encomienda de gestión para la realización de trabajos científico-técnicos de apoyo a la sostenibilidad y protección de las aguas subterráneas. Informe inédito. Centro de documentación del IGME, Madrid, 41 págs.

IGME e INYPSA. 2010. Selección y caracterización de áreas y estructuras favorables para el almacenamiento geológico de $\mathrm{CO}_{2}$ en España. Volumen III-1 Cadena Ibérica y cuencas del Tajo y Almazán -Geología-. Informe interno. 38 págs. + Anejos.

ITGE. 1979. Plan Nacional de Investigación de Aguas Subterráneas (PNIAS): Proyecto de investigación hidrogeológica de la cuenca alta y media del Guadiana. Informe final (Sistema 19: Sierra de Altomira. Sistema 20: de la Mancha de Toledo. Sistema 22: Cuenca del río Bullaque. Sistema 23: Llanura Manchega. Sistema 24: Campo de Montiel. Centro de Documentación del IGME, Madrid, 119 págs. +3 planos.

ITGE. 1997. Unidades hidrogeológicas utilizables para al abastecimiento de poblaciones en Castilla-La Mancha. Convenio entre la Consejería de Obras Públicas de Castilla-La Mancha y el ITGE para el apoyo a la elabora- ción de un plan director regional de abastecimiento de agua a poblaciones. Madrid, 126 págs.

López-Gutiérrez, J., Plata J.L. y Mejías, M. 2013. Caracterización de la divisoria hidrogeológica Guadiana-Júcar en la Llanura Manchega mediante técnicas geológicas geofísicas. Boletín Geológico y Minero. 124 (3) 381-404.

Martínez-Cortina, L., Mejías, M., Díaz, J.A., Morales, R. y Ruíz, J.M. 2011. Cuantificación de recursos hídricos subterráneos en la cuenca alta del Guadiana. Consideraciones respecto a las definiciones de recursos renovables y disponibles. Boletín Geológico y Minero, 122 (1): 17-36.

Martínez-Parra, M. 2013. Hidrogeología de la Serranía de Cuenca. Tesis doctoral, Universidad Autónoma de Madrid, Madrid, 528 págs. + anejos.

Martínez Parra, M. y Díaz Muñoz, J. A. 2013. Propuesta de zonificación hidrogeológica de las masas de agua subterránea (041.001) Sierra de Altomira y (041.005) Rus-Valdelobos. Boletín Geológico y Minero, 124 (3): 351-365.

Mejías, M. 2014. El agua protagonista a través de los siglos. En: Mejías, M. (ed.). Las Tablas y Los Ojos del Guadiana: agua, paisaje y gente. IGME-OAPN, Madrid: 15-64.

Muñoz-Martín, A. 1997. Evolución geodinámica del borde oriental de la cuenca del Tajo desde el Oligoceno hasta la actualidad. Tesis Doctoral, Universidad Complutense de Madrid, Madrid, 331 págs. + anejos.

Muñoz-Martín, A. y De Vicente, G. 1998. Cuantificación del acortamiento alpino y estructura en profundidad del extremo sur-occidental de la Cordillera Ibérica (Sierras de Altomira y Bascuñana). Revista Sociedad Geológica de España, 11(3-4), 233-252.

Piña-Varas, P. 2014. Aplicación del método magnetotelúrico a la caracterización de reservorios: Anticlinal de El Hito (Cuenca) y Sistema Geotérmico de Tenerife. Tesis doctoral, Universidad de Barcelona, Barcelona, 192 págs. + anejos.

Querol, R. 1989. Geología del subsuelo de la Cuenca del Tajo. E.T.S.I. Minas de Madrid (Depto. de Ingeniería Geológica), 48 págs.

Sánchez-Soria, P. 1973. Estudio geológico de la Sierra de Altomira (entre paredes y Belmonte). Tesis doctoral, Universidad Complutense de Madrid, Madrid, 297 págs. Sopeña, A. 2004. Cordilleras Ibérica y Costero-Catalana. En Vera, J.A. (ed.), Geología de España. Sociedad Geológica de España e Instituto Geológico y Minero de España, Madrid, 465-528.

Valcárcel-Rodríguez, M.M. 2015. Reconstrucción y restitución 3D del anticlinal de Puerta-Pareja y estudio de su evolución deformacional y cinemática en su contexto regional (Cuenca de Loranca y Sierra de Altomira). Tesis doctoral, Universitat de Barcelona. Barcelona, 270 págs.

Recibido: septiembre 2018

Revisado: diciembre 2018

Aceptado: enero 2019

Publicado junio 2019 